\title{
THE IMPACT OF THE GENDER AND COLLEGE VARIABLES ON THE MATURITY OF THE CAREER AMONG THE FIRST YEAR STUDENTS AT SULTAN QABOOS UNIVERSITY
}

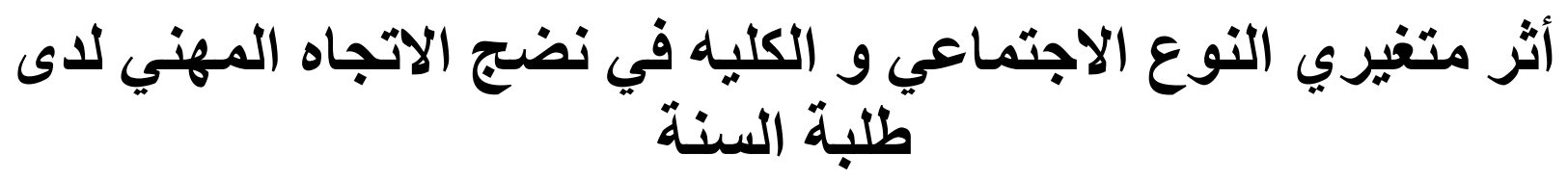

\author{
الأولى بجامعة السلطان قابوس
}

Tarik Hamood Rashid Al-Kharusi ${ }^{1 *}$, Dawood Abdulmalik AL-Hidabi ${ }^{2}$, and Muhammad Ibrahim Al-Safasefa ${ }^{3}$

${ }^{1} \mathrm{PhD}$ candidate in education at the Faculty of Education (IIUM): alkhroosi@moe.om

${ }^{2}$ Prof. Dr. at the Faculty of Education (IIUM): dawood@iium.edu.my

International Islamic University Malaysia

${ }^{3}$ Prof. Dr. at the Faculty of Educational Sciences, Mutah University, Jordan,

dr-mohamadsafa@hotmail.com

${ }^{*}$ Correspondent author

\begin{abstract}
This quantitative study discusses the level of professionalism maturity of students at Sultan Qaboos University in the Sultanate of Oman. The problem is that the lack of professional maturity makes the student hesitant, to chooses the specialization randomly or according to the parents or teachers' opinion, regardless of his inclinations, capabilities, future planning and what the labor market requires. Which leads to a change of specialization, delay in graduation or quit the university. Therefore, the study aimed to diagnose the level of professional maturity of first-year students, and the effect of the gender (male / female) variables, and Faculty (human / scientific). To achieve the objectives the descriptive and analytical method was used. The data collection was based on the (Crates) scale for the maturity of the professional tendency, that was applied on a sample of (328) male and female students. The findings revealed that: The level of maturity of the professional direction was average on the scale as a whole, the field of independence ranked first, the assurance came second, while interest in professional decision-making came last. There were statistically significant differences in the maturity of the occupational orientation attributed to the gender variable; where the differences appeared statistically significant in the area of interest only in favor of males.
\end{abstract}

Keywords: maturity level, professional orientation, Sultan University.

\section{الملخص}

ناقشت هذه الدراسة الكمية مستوى نضـج الاتجاه المهني لدى طلبة جامعة السلطان قابوس بسلطنة عُمان. فالمشكلة إنَّ نقص النضّة المهني يجعل الطالب في تردد، فيختار التخصص عشو ائيا أو 


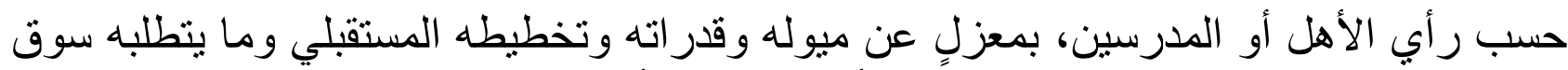

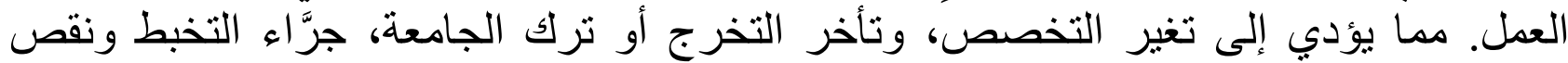

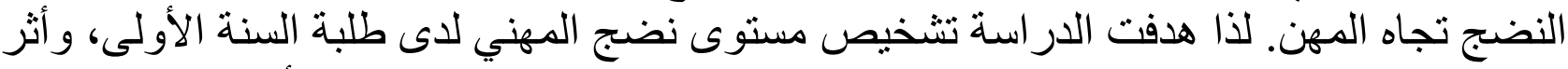

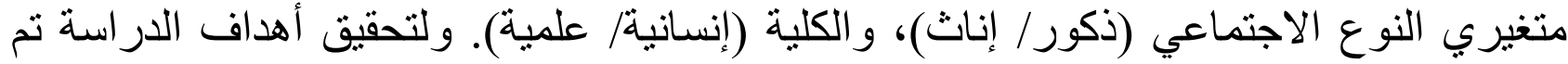

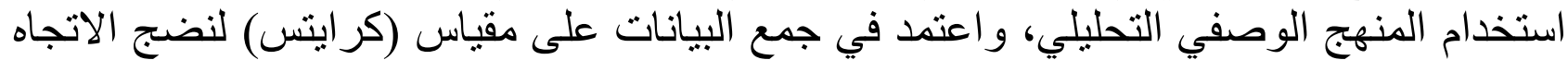

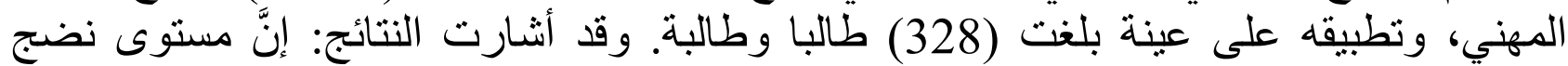

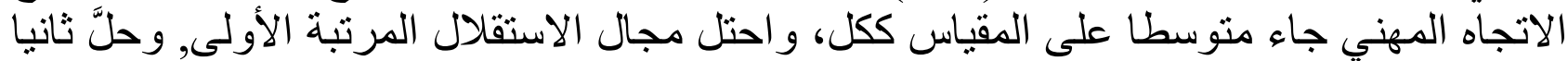

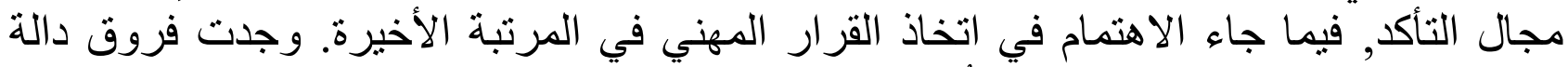

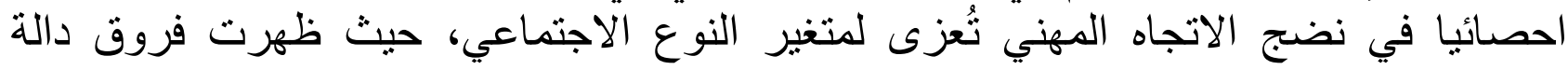

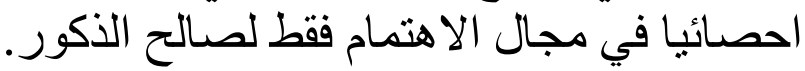
كلمات مفتاحية: مستوى النضج، الاتجاه المهني، جامعة السلطان.

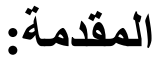

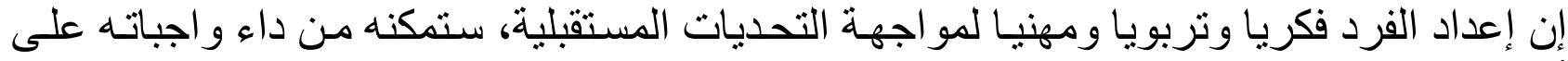

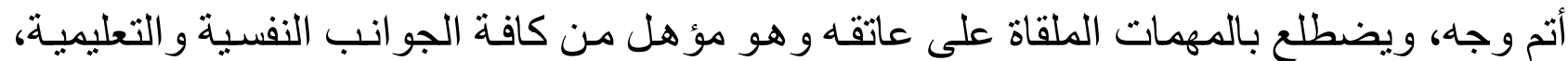

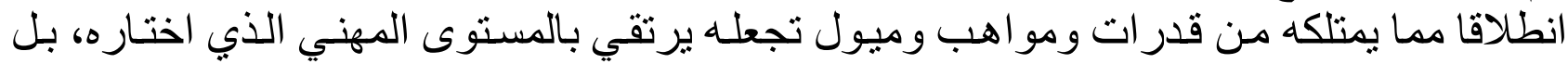

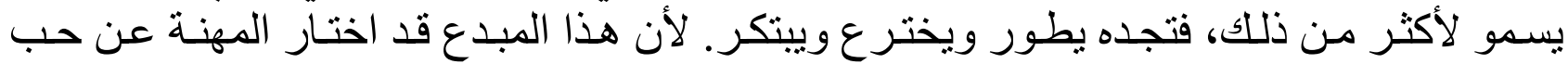

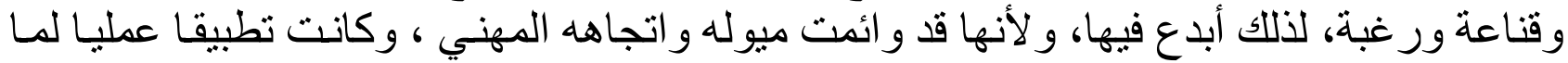

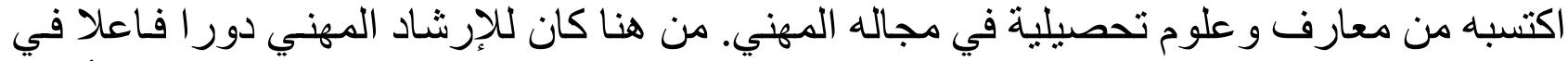

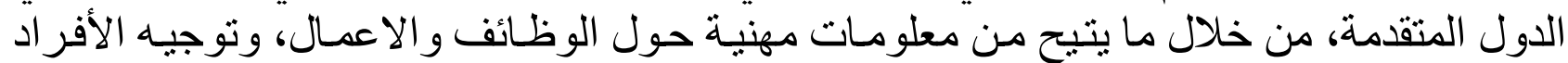

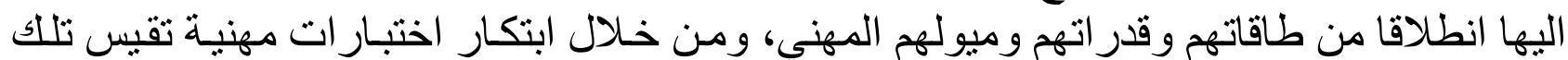

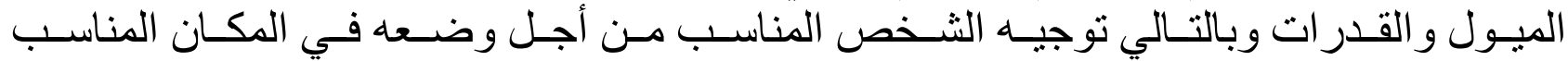

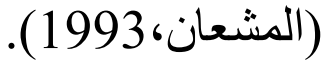

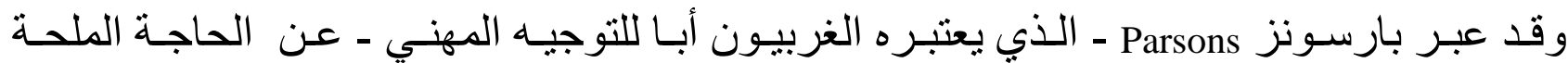

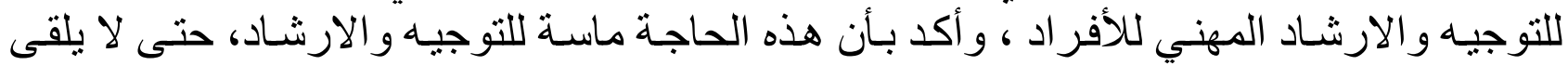

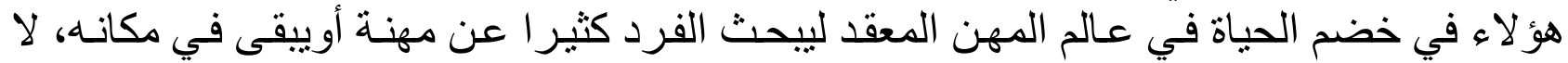

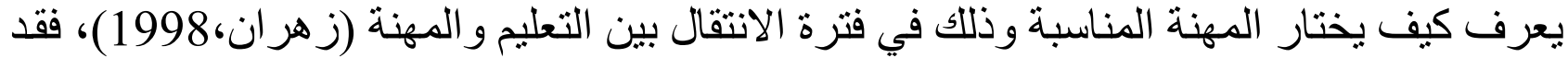

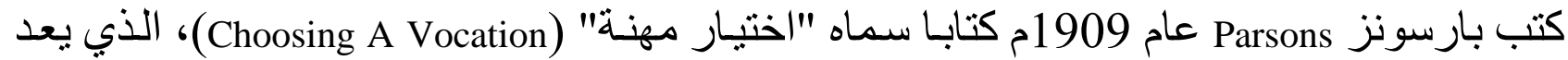

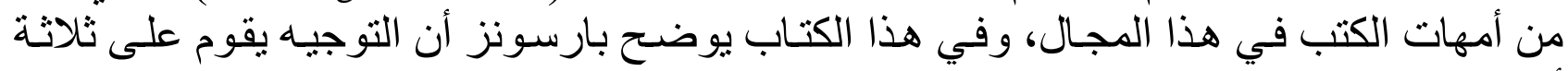

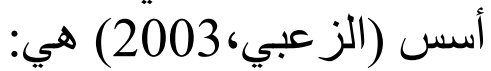
1-در اسة الفرد من حيث استعداداته وقدر اته وميولهي. 2-در اسة المهن المختلفة وما تحتاجه من متطلبات و استعدادات.

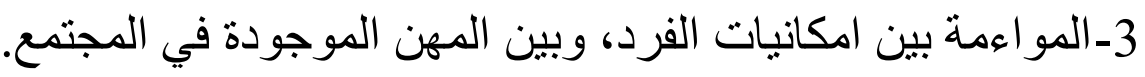

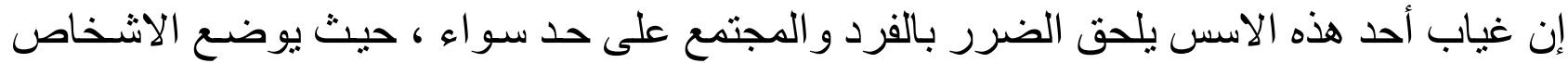

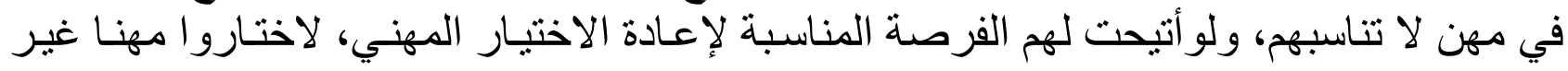


مهنهم، و هذا يتتافى مع مبدأ احتر ام حرية الفرد وتقرير مصيره بنفسه، حيث يقضي الفرد حياته في وني مهنة لا تناسبه، و لا يرضى عنه ونها وغير سعيد فيها، مما بعني ضياع الكثير من الطاقات التي يحتاج إليها المجتمع دون فائدة.

فكل جانب من جو انب التوجيه و الإرشاد التي وضعها بارسونز يؤثر بطريقة مباشرة على المردود

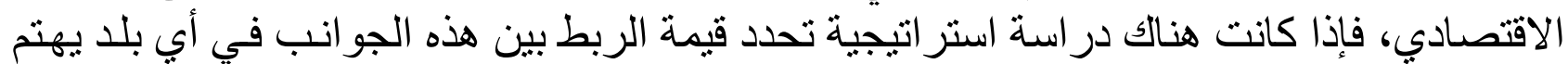

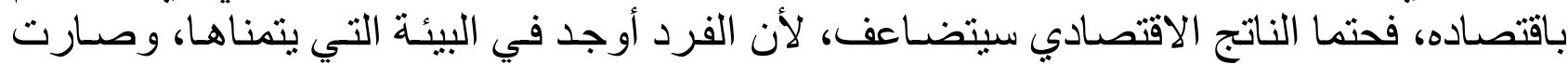
جزءا من حياته وتكوينه النفسي و العملي، والارشاد المهني هو الذي يساعد الفرد في اختبار مهنته

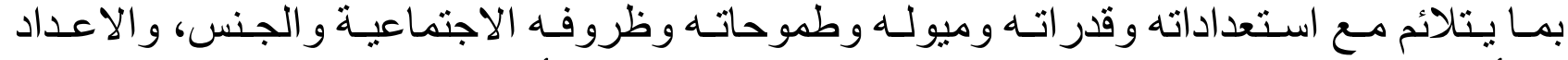

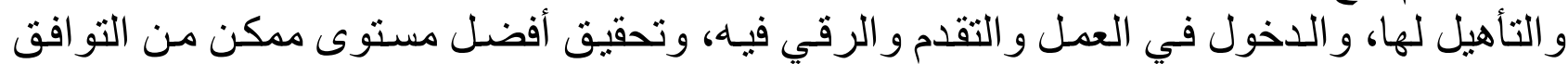

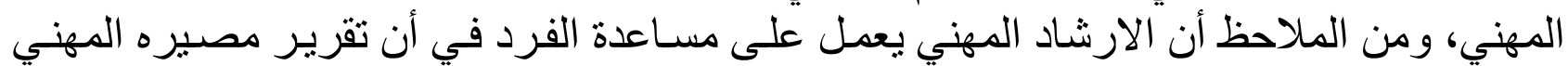

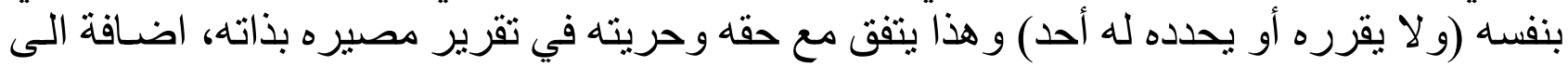

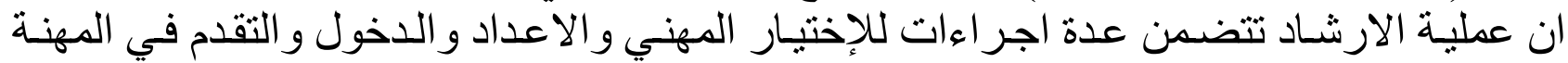

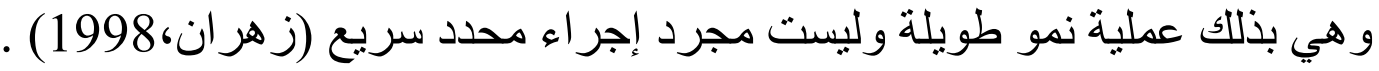

وقام سوبر Super بتطوير أول نموذج للنضه المهني في أواخر الخمسينات في در اسـة لأنمـاط المهنة

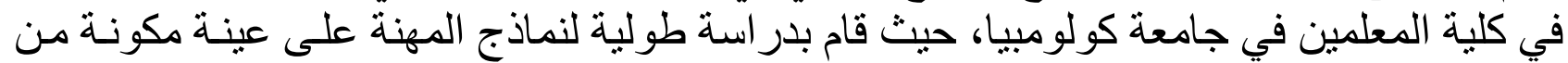

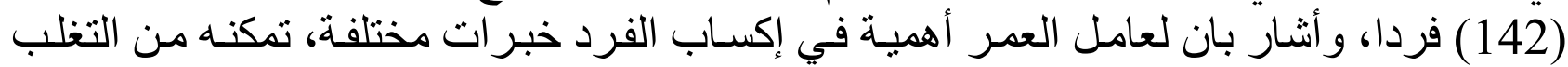

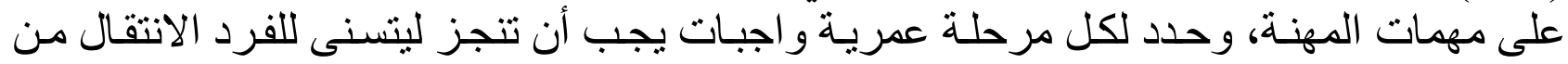

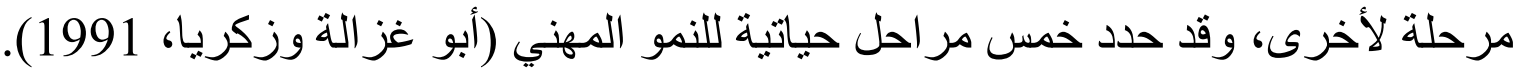

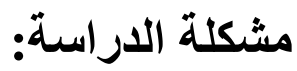

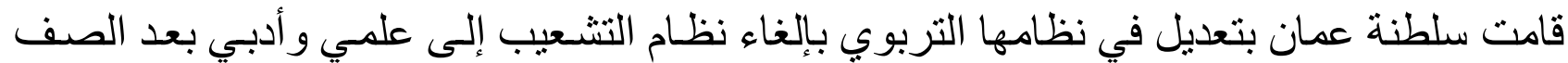

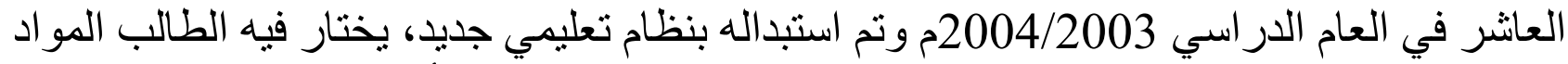

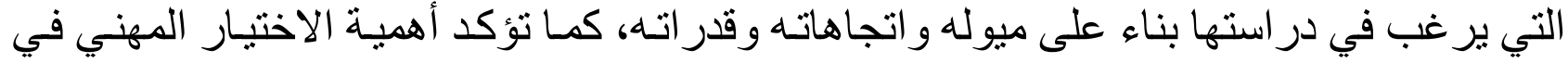

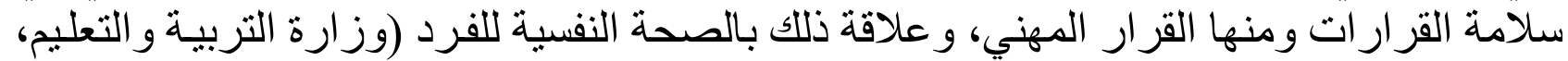

. $(2003$

إنَّ عمليـة الاختيـار بعـد الصـف العاثـر سـيترتب عليهـا الكثيـر مـن القـرار ات و القضــايا الخاصــة مستقبلا، فهي ستحدد تحصبل الطالب في الصفين الحادي عثر و الثاني عثـر ، كمـا ستحدد الكليـات

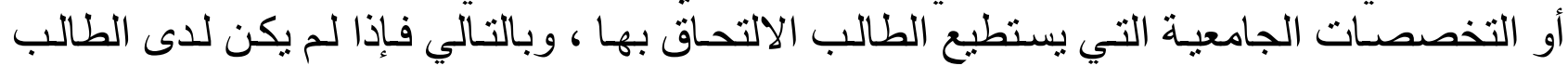
نضج مهني فإنه سيختار التخصص، إمـا مصسادفة أو حسب ر أي الأهل أو المدرسين أو الأصددقاء

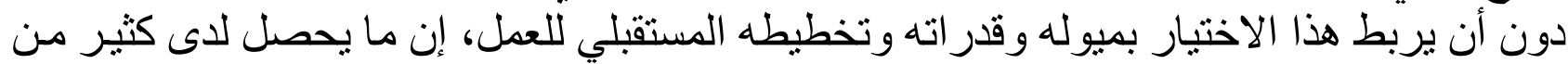

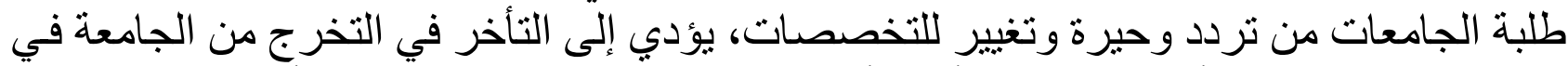

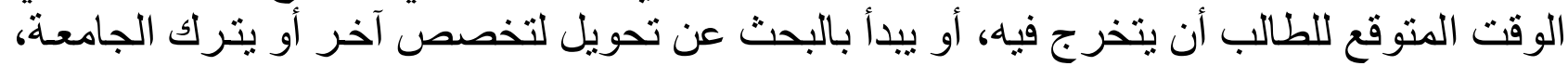

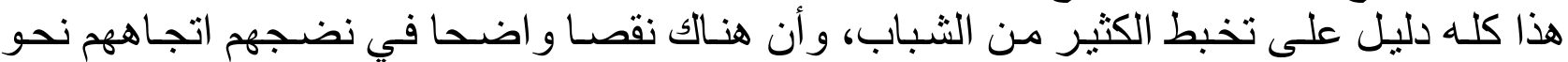

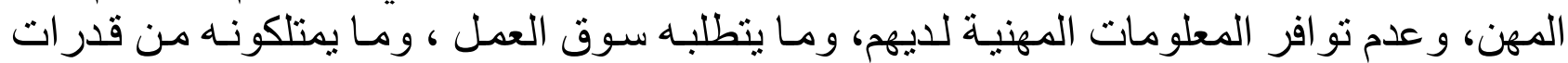

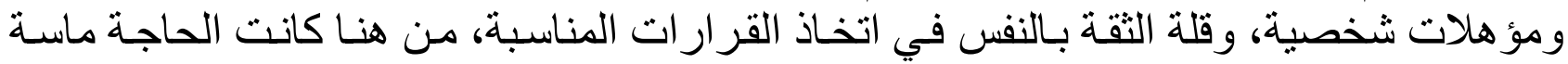

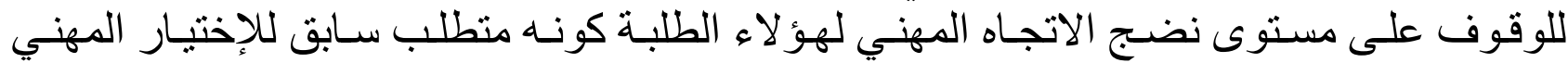
السليم، لذلك جاءت هذه الدراسة بهدف الكثنف عن مستوى نضـج الاتجـاه المهني لدى طلبة السنة 
الأولى في الجامعة كون التخصص الفعلي سيكون في نهايـة هذه السنة، وبالتحديد فإنها تحاول الإجابة عن السؤ الين التاليين:

1-ما مستوى نضج الاتجاه المهني لدى طلبة السنة الأولى في جامعة السلطان قابوس؟

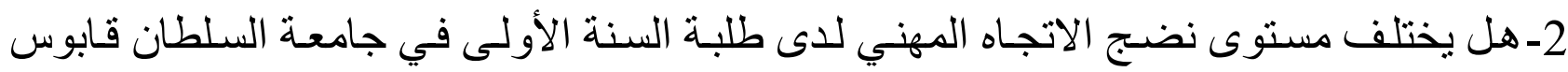
باختلاف النوع الاجتماعي(ذكور ، إناث) و الكلية (انسانية، علمية) و التفاعل بينهما؟

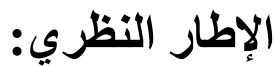
قياس النضج المهني: هناك العديد من القو ائم التي صممت تحديدا لقياس وتقييم النضـج المهني، ومن أهم تلك الكقائيس:

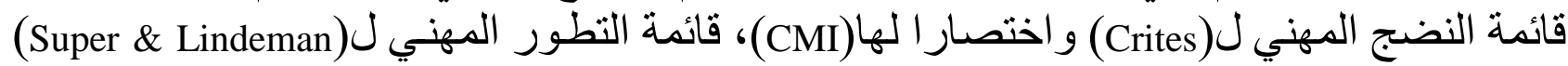
Adult Career Development Inventory

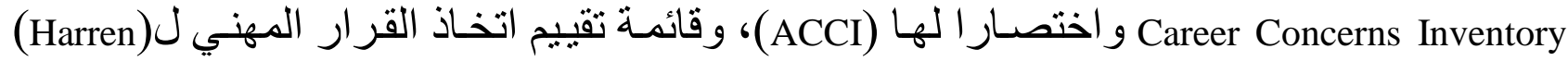
Assessment of Career Decision Making Career Beliefs Inventory (Krumbolltz) Career Decision Scale (Osipow)

أما كر ايتس (Crites) فقد اقترح نموذجا للنضج المهني و الذي يشتمل على بعدين: التأثير أو الانفعال

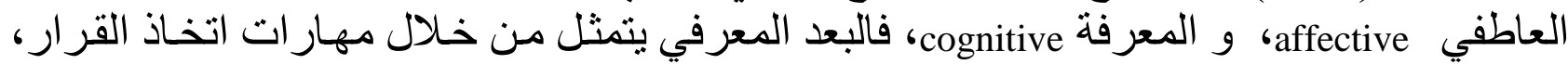

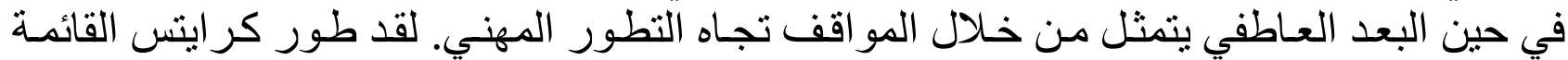

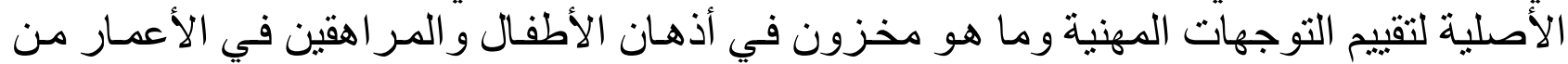

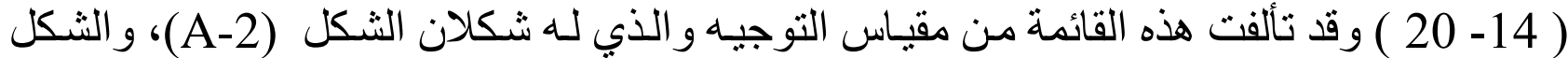

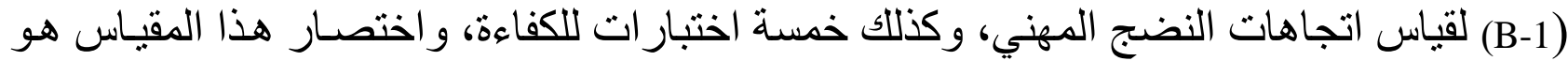

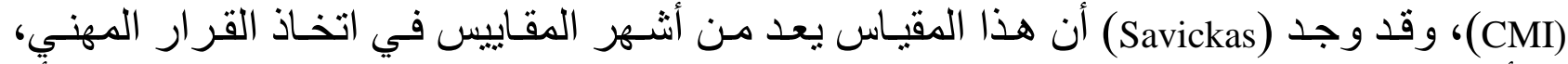

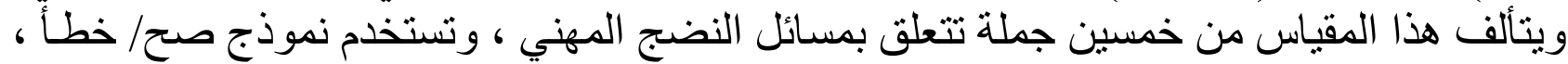

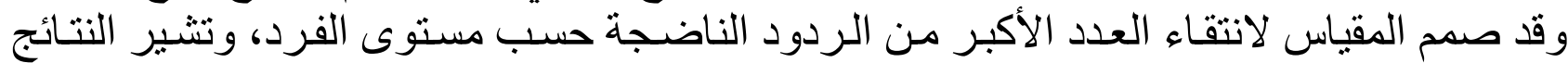

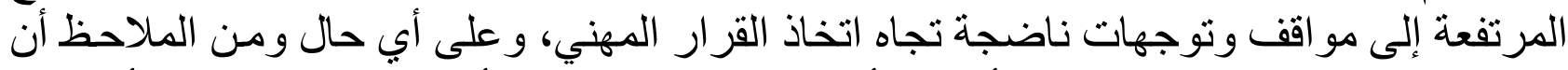

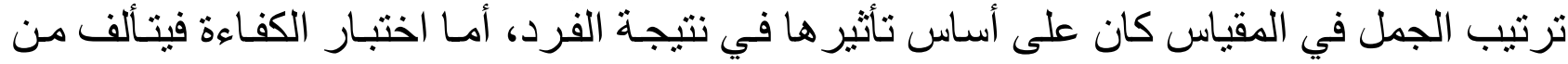

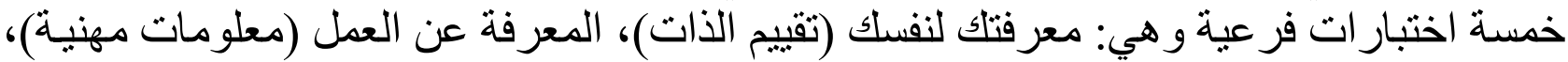

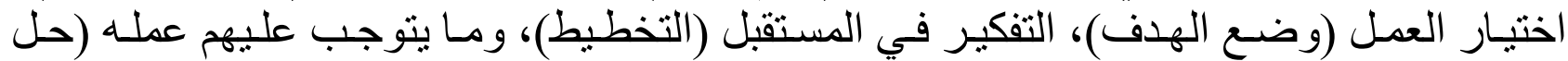

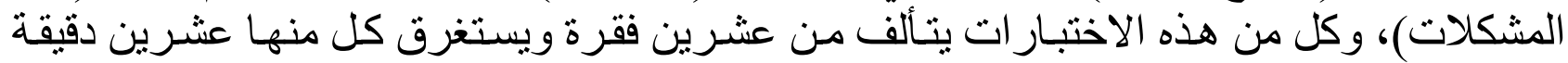

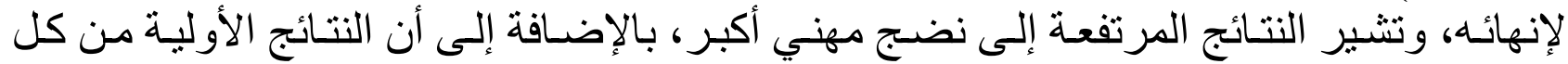
مقياس من هذه المقاييس يمكن أن تحول إلى نتائج نسبية ونتئية ونتائج معيارية.

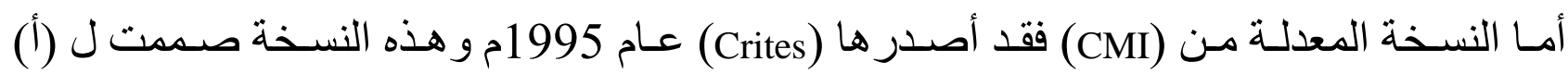

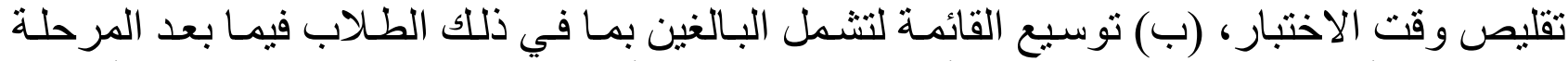

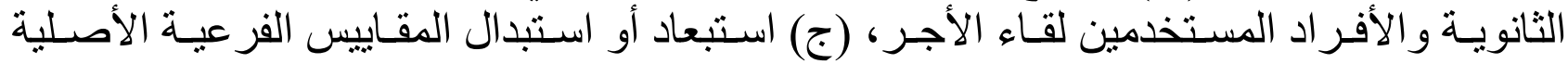

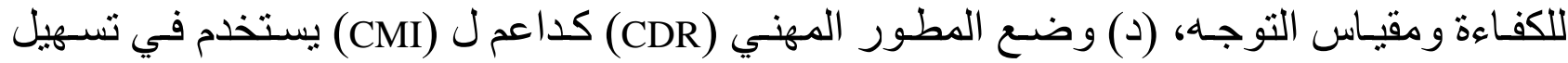

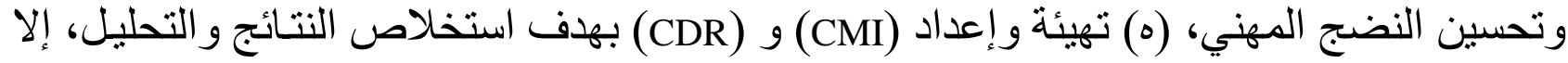




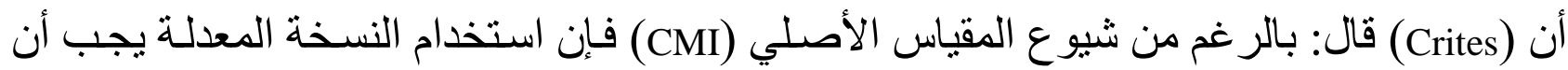

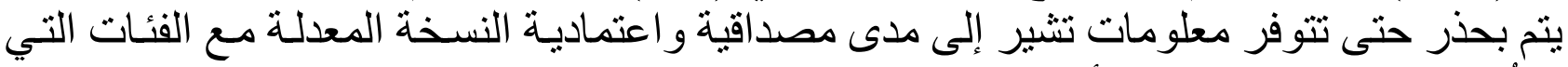

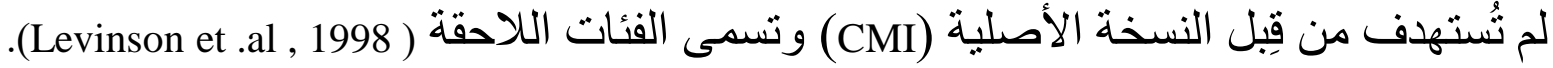
الدر اسات السابقة:-

\section{الدراسات التي تثاولت التضج المهني وعلاقته ببعض المتغيرات.}

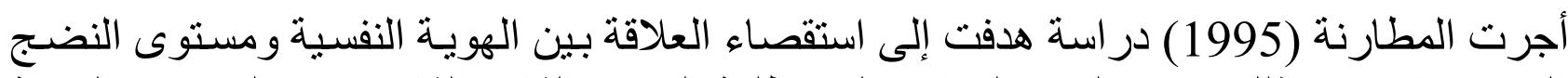
المهني و اختلاف ذلك حسب الفرع الدراسي لدى طلبـة الصف الثاني الثانوي في المدارس التابعـة لوزارة التربية و التعليم في محافظة الكرك للعام 1994/93، على عينة شملت (522) طالبا وطالبة

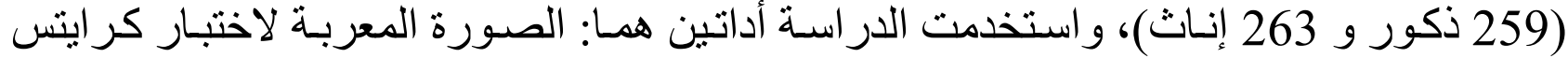

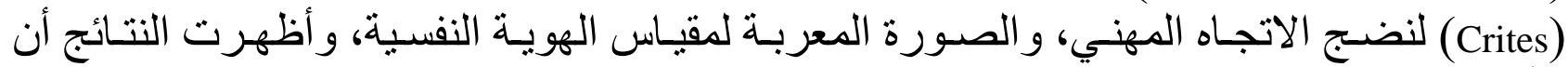

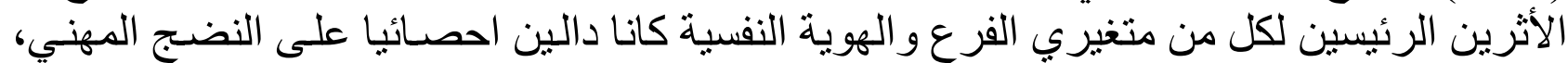

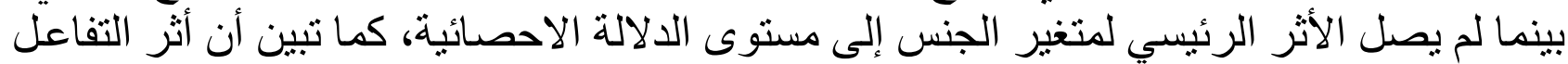

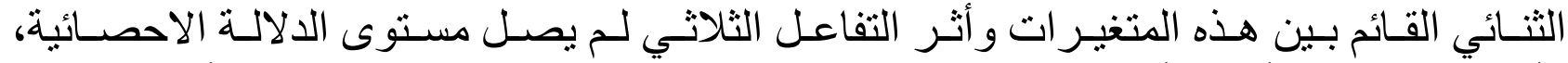

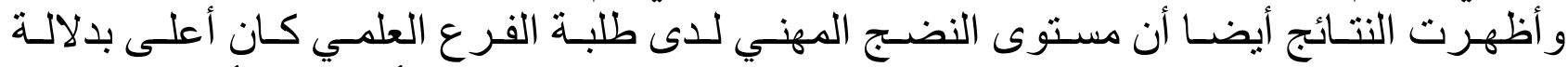
احصائية من مستوى النضج المهني لدى كل من طلبة الفرعين المهني و الأدبي، كما أثارت الني النتائج

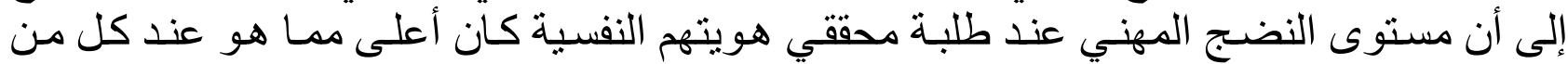
الطلبة من مستوى منغلقي الهوية ومضطربي الهوية ومؤجلي الهويسة، وأن مستوى النضـج المهني هوني

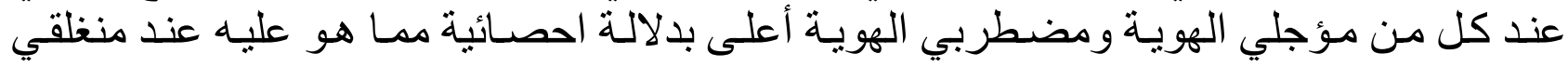
الهوية.

وفي در اسة و اين ومارك (Wayne and Mark, 1997) التي هدفت إلى تحري العلاقة بين السلوك

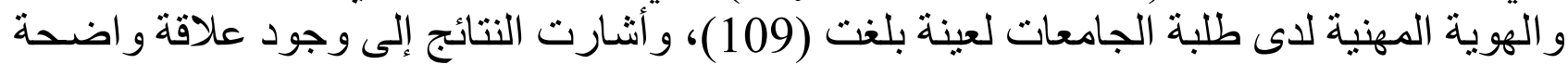

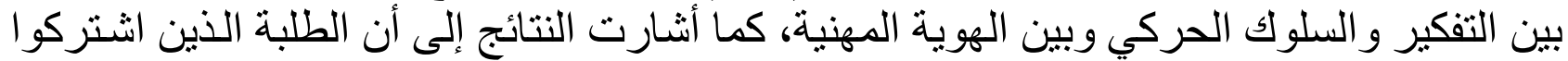
في نشاطات إبداعية ومعرفية كانوا متقدمين من حيث تحقيق الهوية المهنية.

الاراسات التي تناولت النضج المهني وعلاقته بالتوع الاجتماعي.

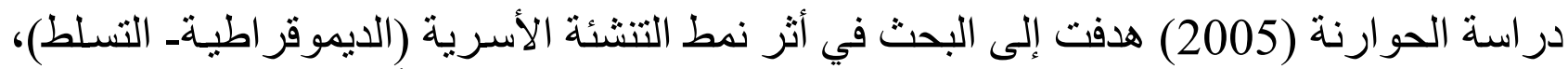
(حماية زائدة- إهمال)، و الجنس في النضـج المهني لدى طلبـة الصف الهـ الأول الثانوي في محافظة الكرك، على عينة تكونت من (488) طالبا وطالبة من المدارس التابعة لمديريات التربية و والتعليم

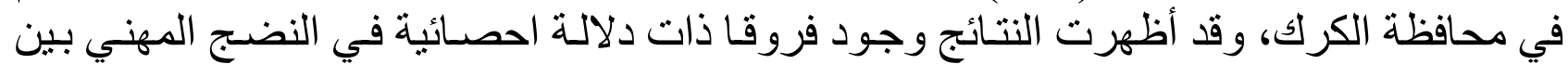

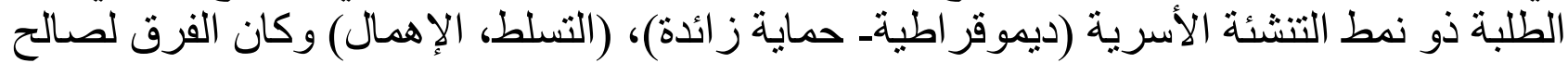

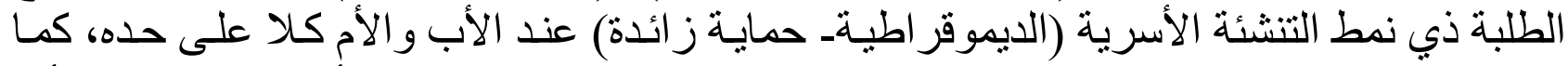

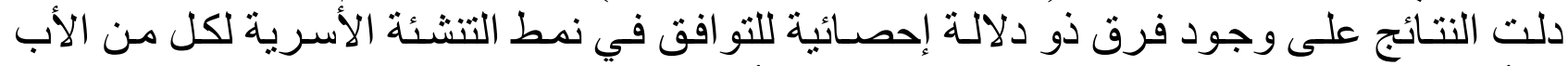

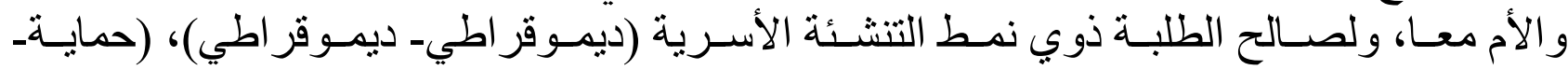

كمـا أجـرى الغـافري (2005) در اسـة بعنـوان النضــ المهنـي لـدى طلبـة الصـف العاثـر بمنطقة 
الباطنة بسلطنة عمان و علاقته ببعض المتغير ات، هدفت هذه الدراسـة الى معرفة مستوى النضـج المهني، و علاقته بمتغير ات التحصبل و الجنس ومكان السكن لدى عينـة مكونـة مـن (1424) طالبـا وطالبة منهم (624) طالبا و (800) طالبة من طلبة الصف العاتثـر بمنطقة الباطنـة شمال، سلطنة

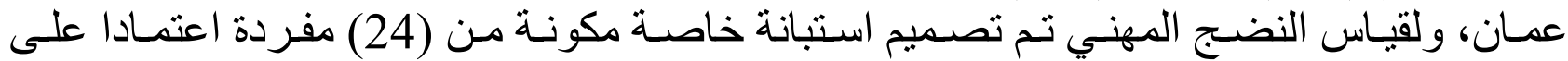
الصورة المعربة لاستبانة كر ايتس للنضـج المهني والتي عدلها جروان في الاردن عـام (1986)،

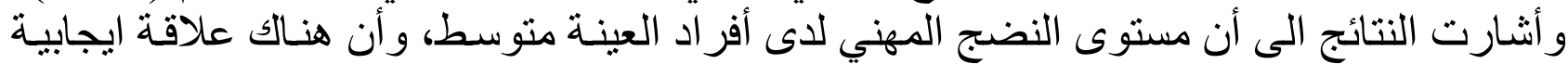

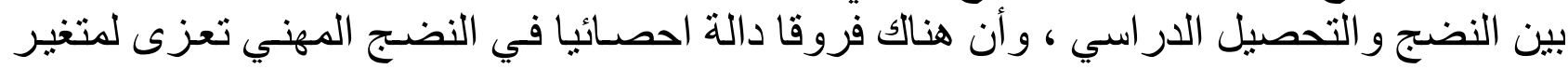
الجنس لصالح الاناث، في حين لم تظهر فروق بين طلبة القرية وطلبة المدينة.

المنهجية والإجراعات

مجثمع الدراسة

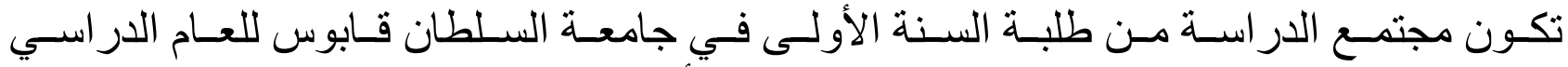

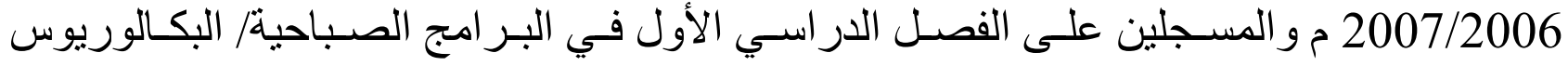

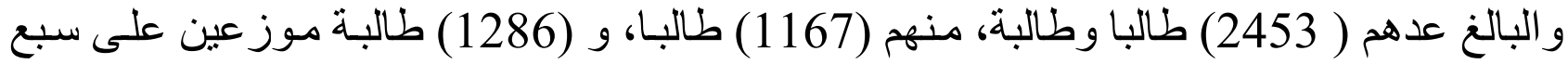

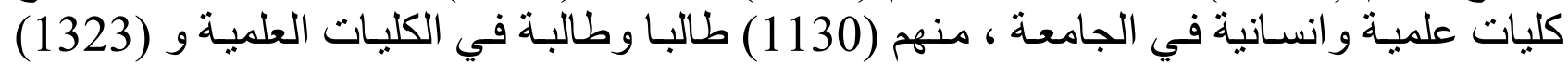

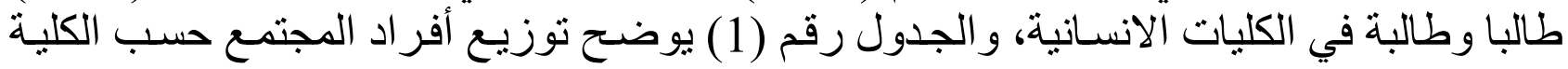
و الجنس (جامعة السلطان قابوس، 2006).

\section{عينة الاراسة:}

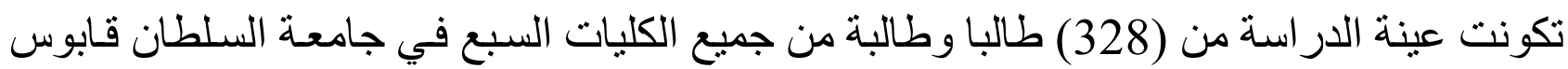

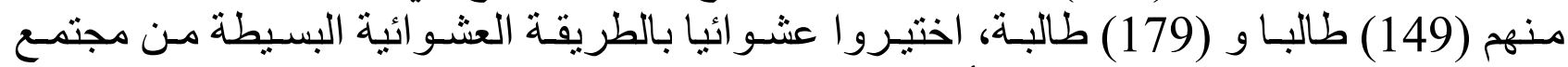

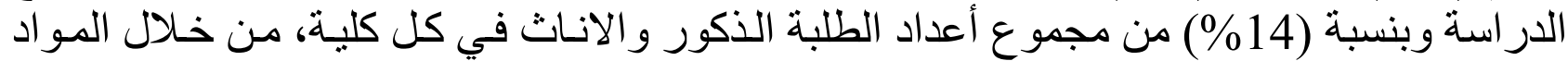

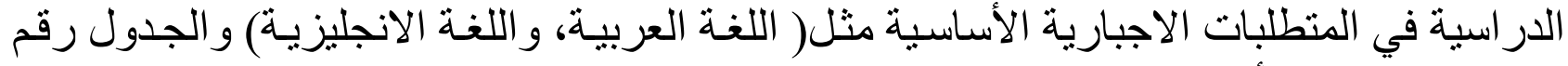
(1) يوضح توزيع أفر اد العينة حسب النوع الاجتماعي و الكليات الانسانية و العلمية. جدول رقم (1) توزيع أفر اد العينة حسب النوع الاجتماعي و الكلية

\begin{tabular}{|c|c|c|c|}
\hline المجـــوع & الإنسانيــة & العلميــــة & \\
\hline 149 & 72 & 77 & ذكور \\
\hline 179 & 106 & 73 & إنـاث \\
\hline 328 & 178 & 150 & المجموع \\
\hline
\end{tabular}

أداة الدراسة

أداة قياس النضج المهني

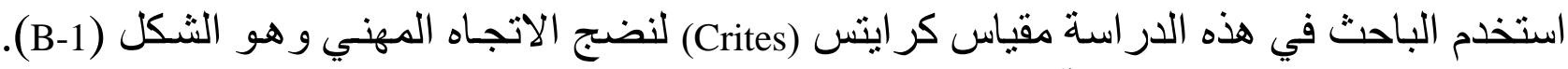

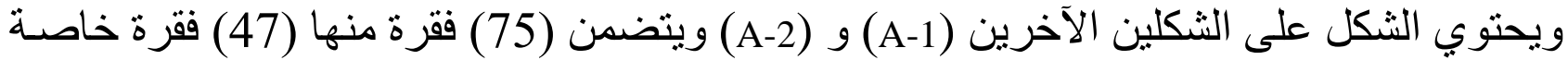

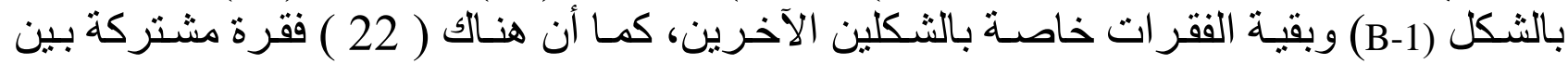




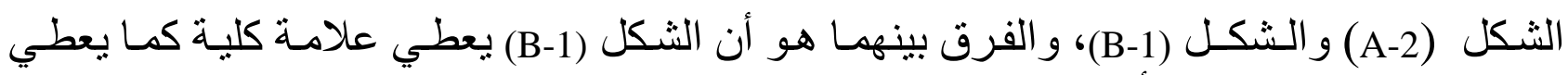

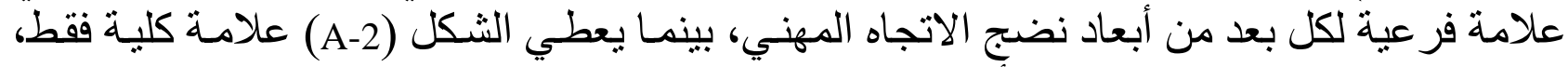

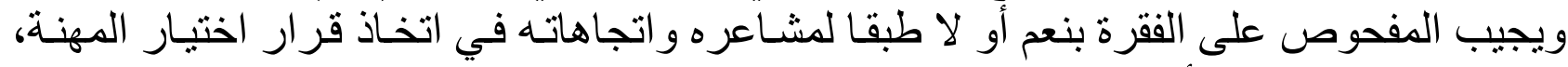

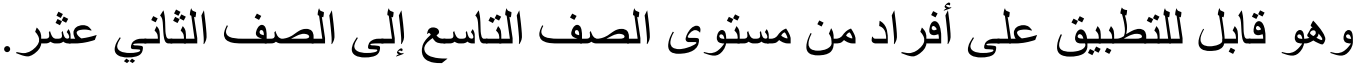
صدق وثبات المقياس:

استخرج صدق المقياس للثكل (B-1) بتحليل احصائي وذلك برسم منحنيات الفقرات للشكل القديم (A-2) على الفقر ات للثكل (B-1) وقد تطابقت المنحنيات في أكثر من الثلثين منها وأهملت البقيـة

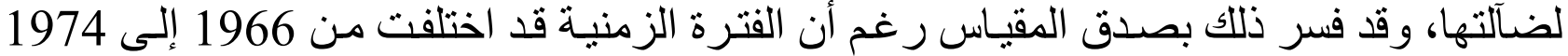

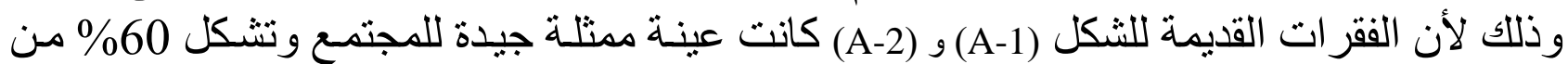

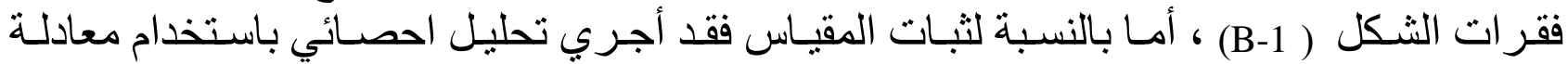

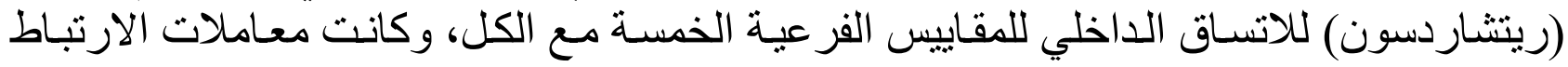

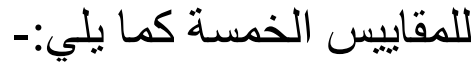

$$
\begin{aligned}
& \text { 0.67لبعد التأكد في اتخاذ قرار المهنة. }
\end{aligned}
$$

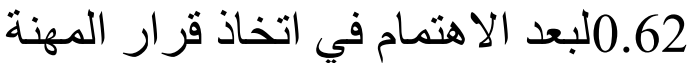

$$
\begin{aligned}
& \text { 0.71لبعد الاستقلال في اتخاذ قرار الإد المهنة } \\
& \text { 0.72لبعد توفر المعلومات في اتخاذ قرار المهنة } \\
& \text { 0.50لبعد المرونة في اتخاذ قرار المهنة }
\end{aligned}
$$

و اعتبرت هذه القيم مقبولة، لأن هذا المقياس يختلف عن اختبار ات التحصبل والاستعداد، حيث أنه

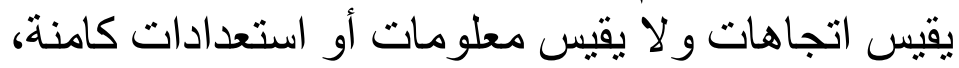
علما بأن عدد فقرات المقياس هي(47) فقرة موز عة على (5) مجالات هي:

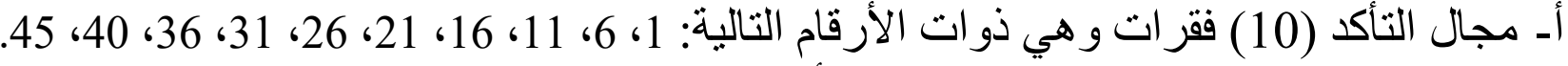

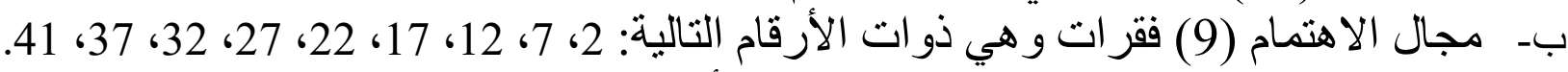

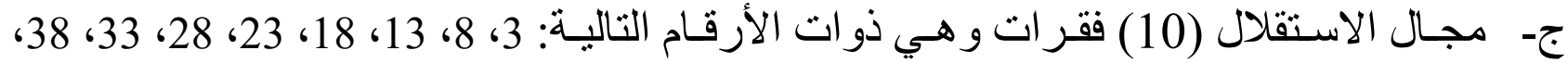
46، 46 دـ - مجـال توفر فر المعلومـات (10) (10) فقر ات وهي ذوات الأرقام التاليـة: 4، 9، 14، 19، 24، 29، 34،

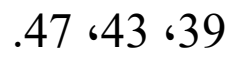

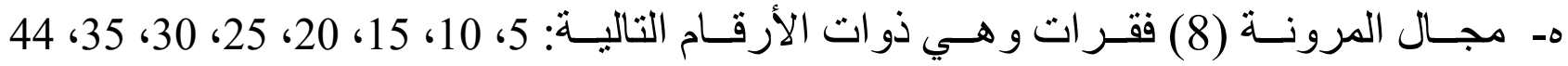

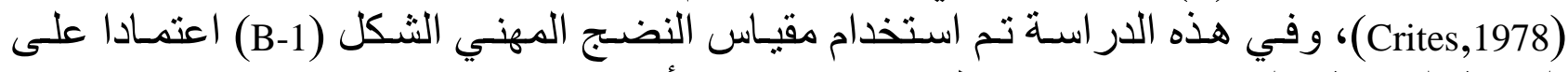
النسخة المعربة و التي قام بترجمتها مطر (1986) في الأردن. وللتأكد مـن دلالات صـدقه وثباتـه لأغـر اض هذه الدر اسـة؛ فقد تـم توزيـع مقيـاس النضـج المهنـي

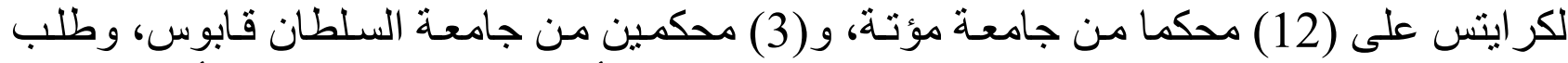

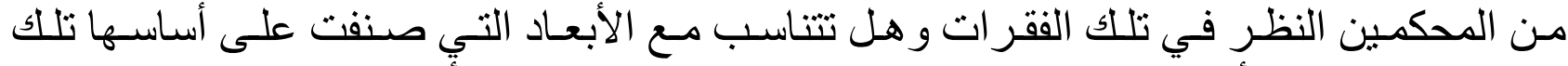

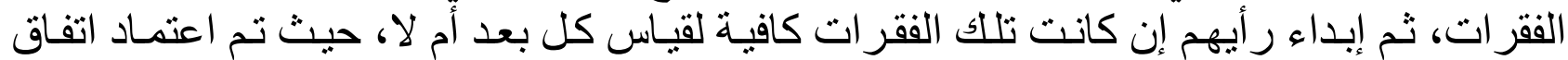
(1\%) ) كنسبة مقبولة للفقرة. الاراسة التجريبية: 


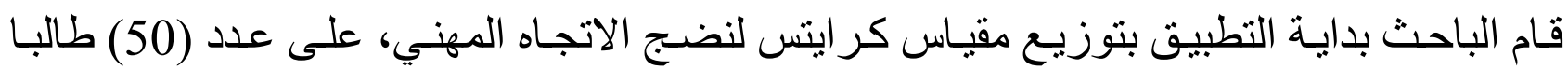

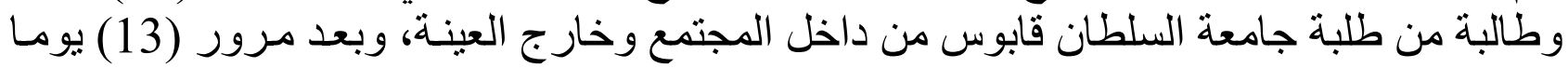
تم إعادة تطبيق الاختبار على نفس الطلبة، والجدول رقم (2) يوضح التح معاملات الثبات للمقياس ككل

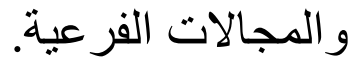

جدول رقم (2) قيم الثبات لكل مجال من مجالات المقياس

\begin{tabular}{|c|c|}
\hline معامل الثبــــات & المجـــال \\
\hline 0.811 & التأكد (10) فقر ات \\
\hline 0.713 & الاهتمام (9) فقر ات \\
\hline 0.744 & الاستقلال (10) فقرات \\
\hline 0.790 & توفر المعلومات (10) فقرات \\
\hline 0.759 & المرونة (8) فقر ات \\
\hline 0.7951 & المقياس ككل \\
\hline
\end{tabular}

المصدر: و هذه القيم مناسبة لأغر اض هذه الدر اسة كما أثنار إليها النبهان(2004).

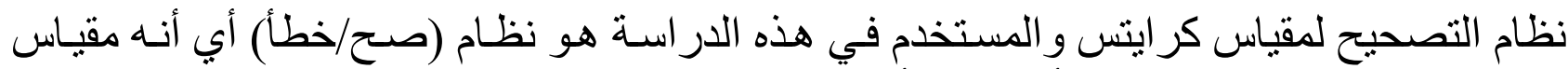

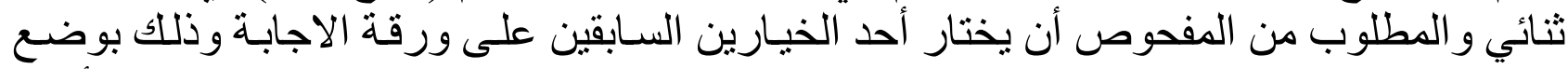

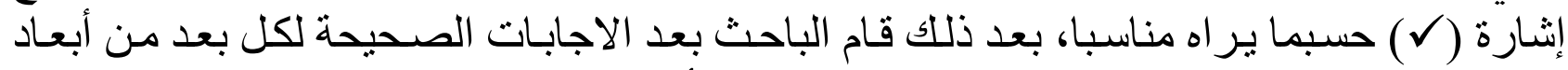

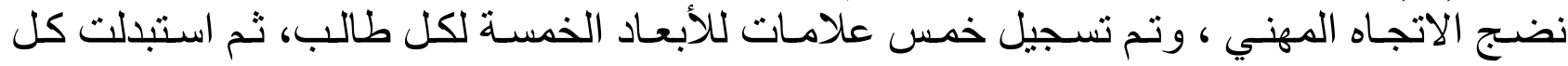

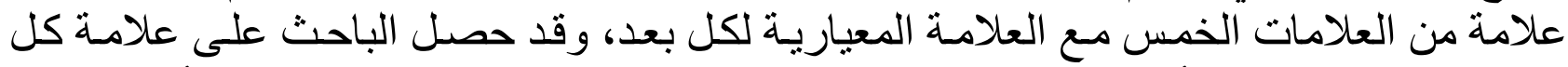

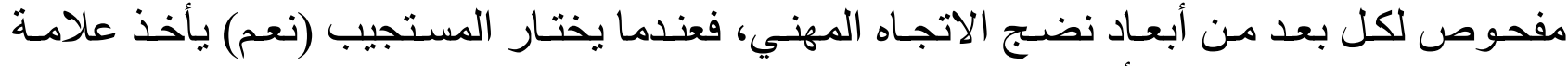

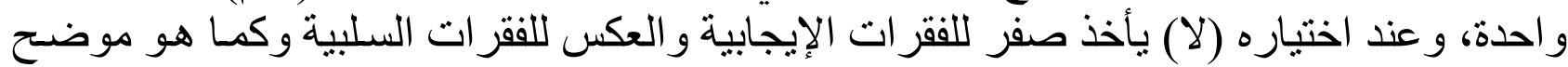
حسب مفتاح تصحيح المقياس.

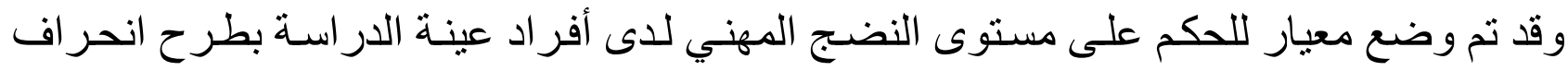

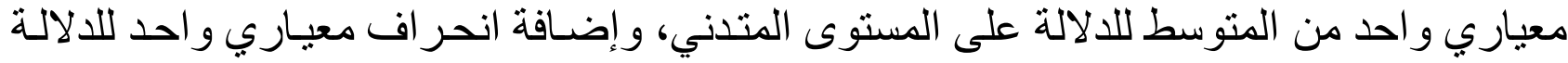

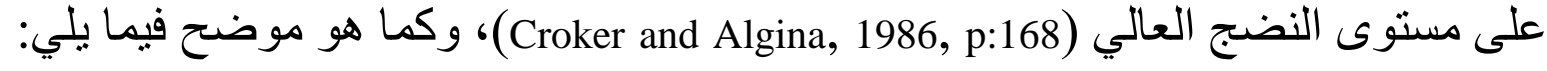
جدول رقم (3) معيار للحكم على مستوى النضج المهني

\begin{tabular}{|c|c|c|c|}
\hline المستوى & النتيجة & عدد الفقرات & المجال \\
\hline متوسطٍ & من 3.342 من 3.342 فأكلى 5.1 فأكثر & (10) فقر ات & المجال الأول: التأكد \\
\hline متوسطٍ & من 2.953 2.953 فألَّي -4.6 من 4.7 فأكثر & (9) فقرات & الالاهنمام الثاني : \\
\hline متوسطٍ & من 3.342 فن 3.342 ألىى 5.2 فأكثر 5.1 & (10) فقر ات & المجال الثالث: \\
\hline متدنٍ & 3.342 فأقلّ & & المجال الر ابع: توفر \\
\hline
\end{tabular}


IJASOS- International E-Journal of Advances in Social Sciences, Vol. VII, Issue 19, April 2021

\begin{tabular}{|c|c|c|c|}
\hline متوسط & من 5.342 فأكثى 5.2 فن 5.1 & (10) فقر ات & المعلو مات \\
\hline متونٍ & 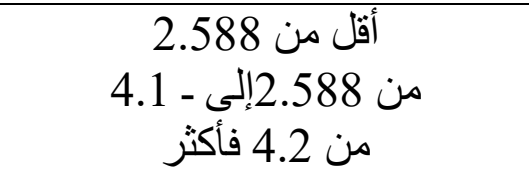 & (8) فقر ات & المجال الخامس: \\
\hline متونٍ & من 17.822 - 17.822 فأكثر 29.378 من 29.4 & (47) فقرة & المقياس ككل \\
\hline
\end{tabular}

عرض النتائج النتائج المتعلقة بالسؤال الأول:

ما مستوى نضج الاتجاه المهني لدى طلبة السنة الأولى في جامعة السلطان قابوس؟ بالوك

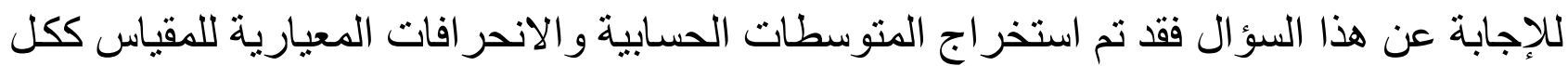

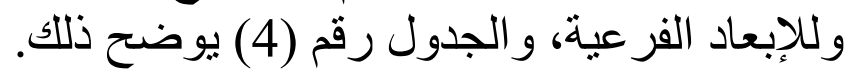

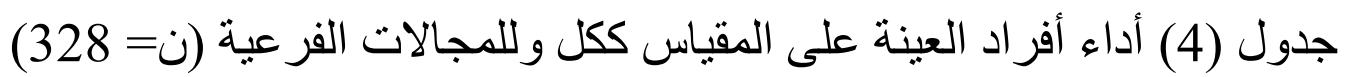

\begin{tabular}{|c|c|c|c|}
\hline الترتيب & الانحراف المعياري & المتوسط الحسابي & المجــال \\
\hline 2 & 1.758 & 5.442 & التأكد الت \\
\hline 5 & 1.647 & 3.378 & الاهتمام \\
\hline 1 & 1.708 & 5.570 & الاستقلال \\
\hline 4 & 2.236 & 4.561 & توفر المعلومات \\
\hline 3 & 1.512 & 4.378 & المرونة \\
\hline- & 5.778 & 23.357 & الكلى \\
\hline
\end{tabular}

أنشار الجدول رقم (4) إلى أن المتوسط الحسابي لمجال الاستقلال احتل المرتبة الأولى في مستوى

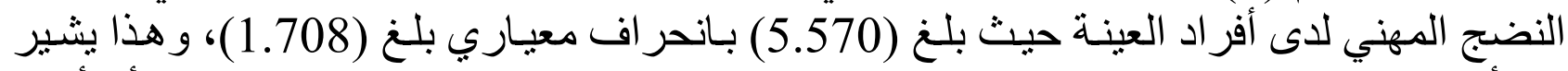

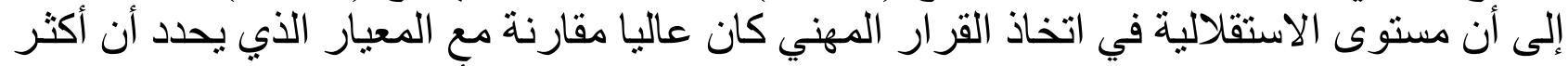

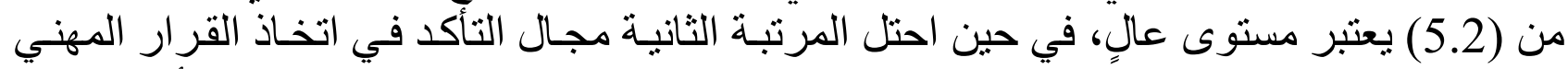

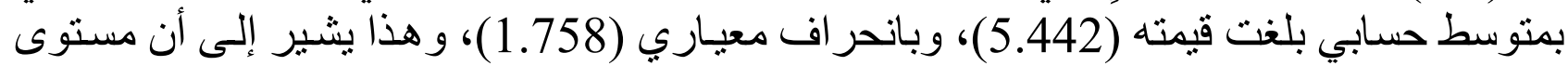

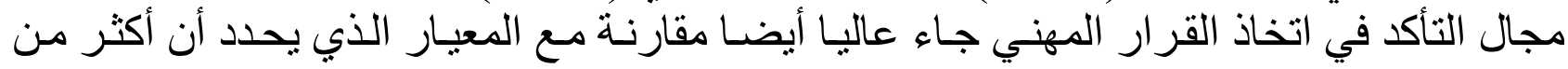

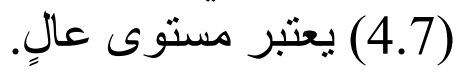

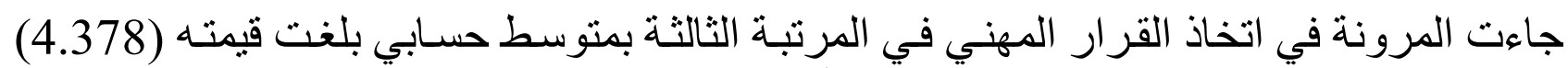

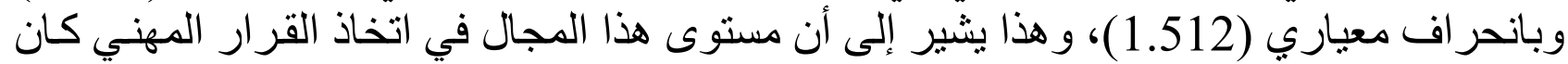

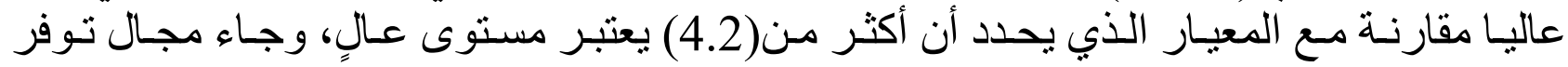

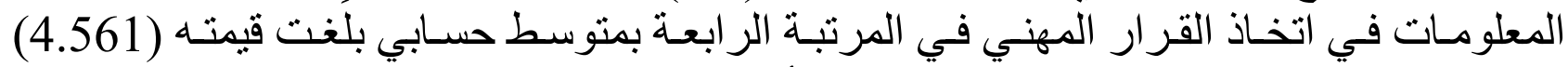

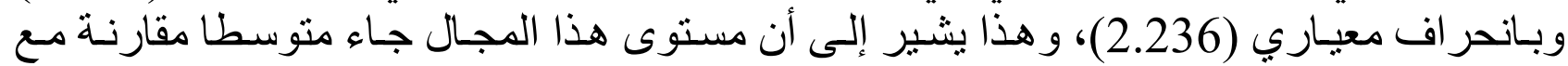

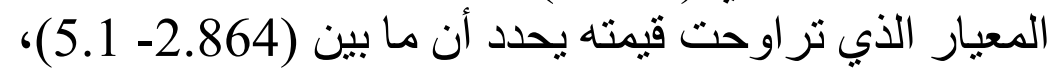




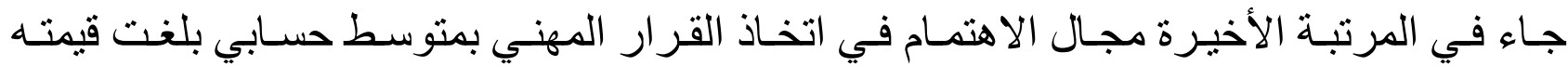

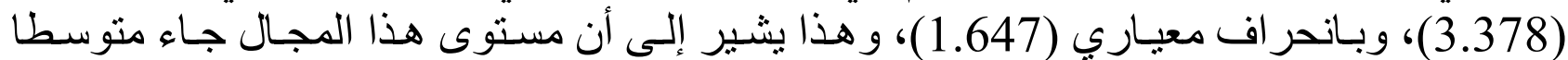

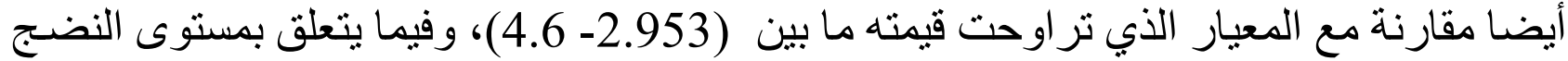

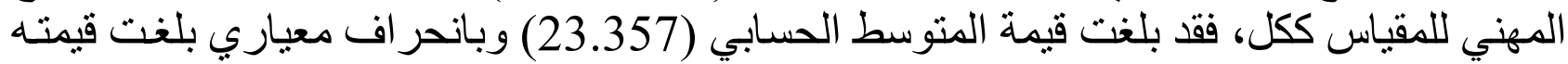

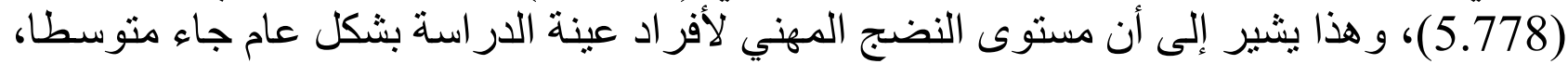

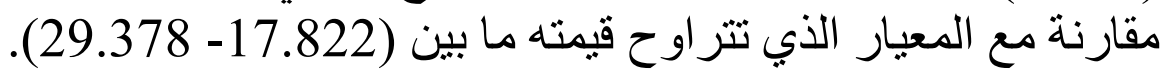

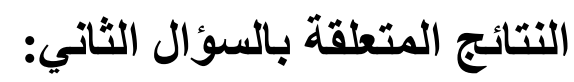

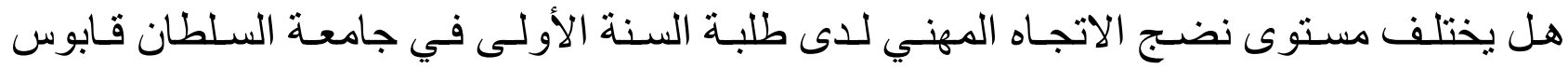

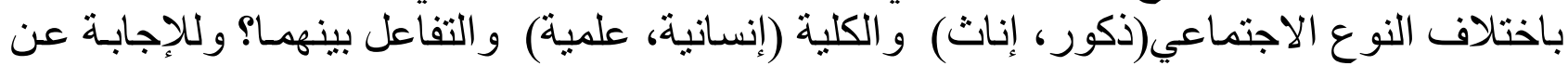

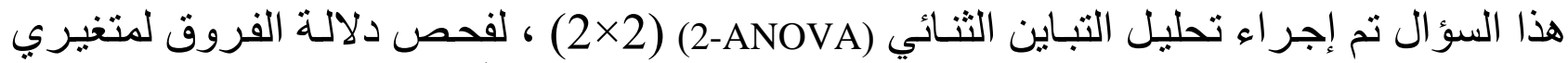

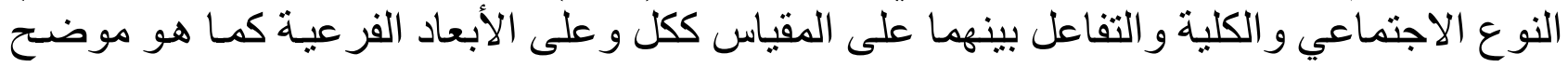

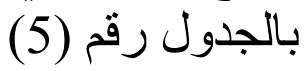
جدول (5) تحليل التباين الثنائي (2×2) لفحص فروق متغيري النوع الاجتماعي و الكلية و التفاعل بينهما

\begin{tabular}{|c|c|c|c|c|c|c|}
\hline مستوى الدلالة & قيم ف & متوسط المربعات & الحرية & المربعات & المجالات & مصدر التباين \\
\hline 0.377 & 0.784 & 2.408 & 1 & 2.408 & التأكد & \multirow{6}{*}{ 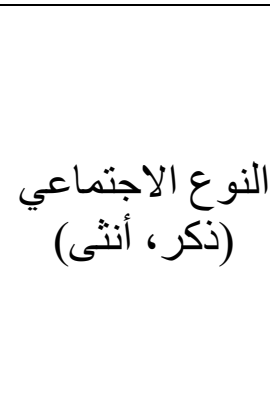 } \\
\hline$* 0.000$ & 14.249 & 36.140 & 1 & 36.140 & الا هتمام & \\
\hline 0.246 & 1.350 & 3.914 & 1 & 3.914 & الاستقلال & \\
\hline 0.627 & 0.237 & 1.166 & 1 & 1.166 & المعلومات & \\
\hline 0.334 & 0.936 & 2.146 & 1 & 2.146 & المرونة & \\
\hline 0.773 & 0.084 & 2.760 & 1 & 2.760 & الكلي & \\
\hline 0.416 & 0.664 & 2.041 & 1 & 2.041 & التأكد & \multirow{6}{*}{ (علمية، إنسانية) } \\
\hline 0.608 & 0.264 & 0.670 & 1 & 0.670 & الاهتمام & \\
\hline 0.277 & 1.186 & 3.438 & 1 & 3.438 & الاستقلال & \\
\hline 0.667 & 0.185 & 0.913 & 1 & 0.913 & المعلومات & \\
\hline 0.730 & 0.119 & 0.272 & 1 & 0.272 & المرونة & \\
\hline 0.908 & 0.014 & 0.446 & 1 & 0.446 & الكلي & \\
\hline 0.056 & 3.691 & 11.342 & 1 & 11.342 & التأكد & \multirow{6}{*}{ النوع الاجتماعي) } \\
\hline$* 0.002$ & 9.778 & 24.800 & 1 & 24.800 & الاهتمام & \\
\hline 0.184 & 1.769 & 5.130 & 1 & 5.130 & الاستقلال & \\
\hline$* 0.009$ & 6.939 & 34.182 & 1 & 34.182 & المعلومات & \\
\hline 0.300 & 1.079 & 2.474 & 1 & 2.474 & المرونة & \\
\hline$* 0.015$ & 5.983 & 197.710 & 1 & 197.710 & الكلي & \\
\hline
\end{tabular}




$$
\text { * دالة احصائيا عند مستوى دلالة (a) = 0.05). }
$$

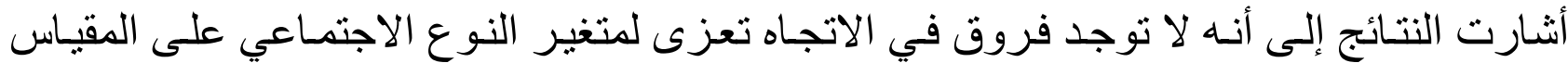

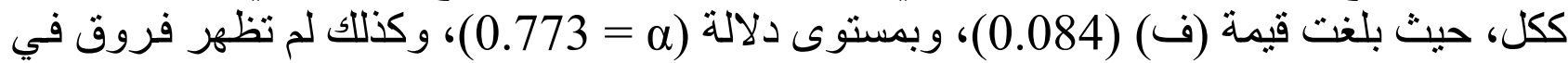

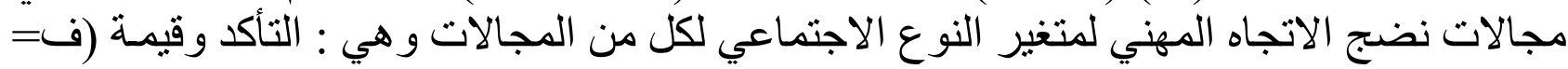

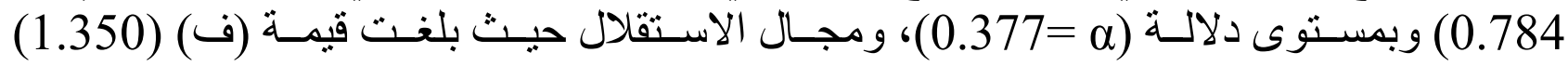

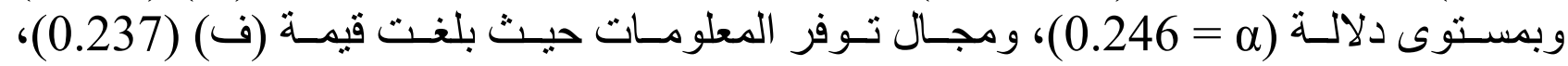

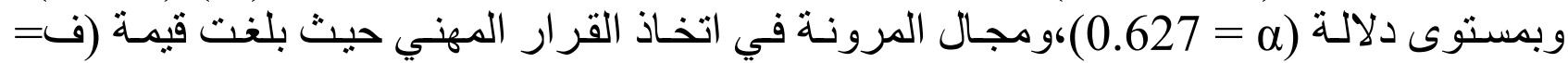

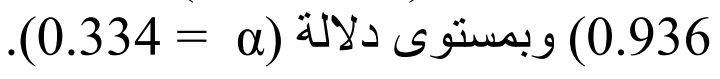

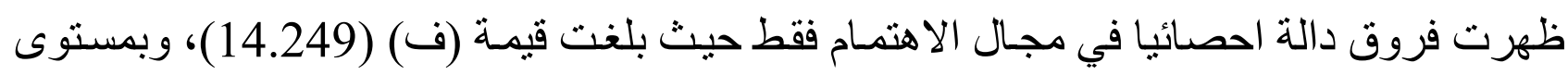

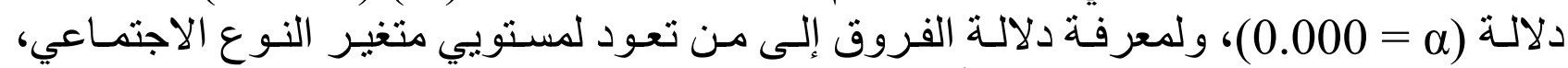

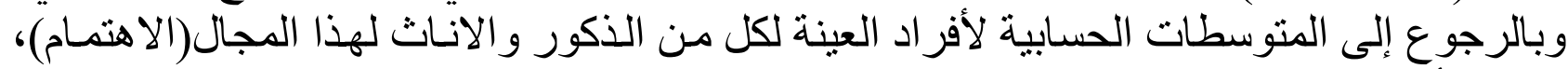

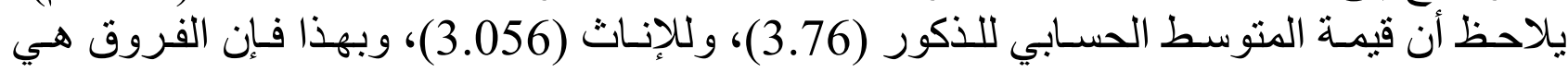
لصالح الذكور.

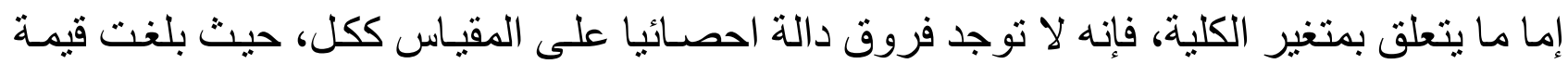

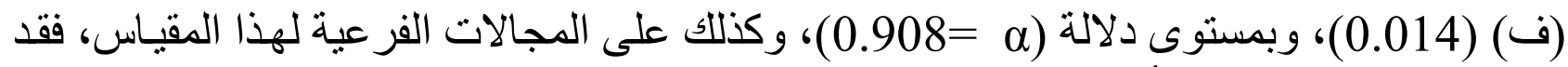

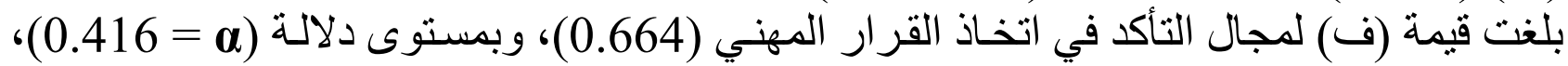

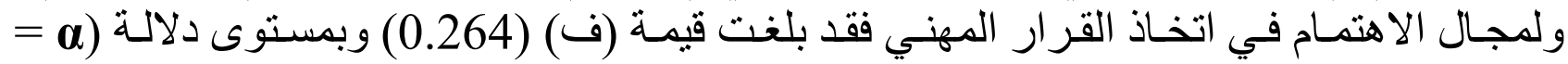

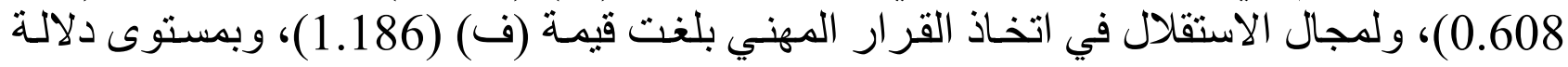

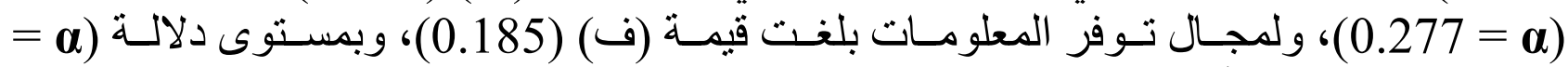
0.667)، و المجال الأخير هو المرونة في اتخاذ القرار المهني.

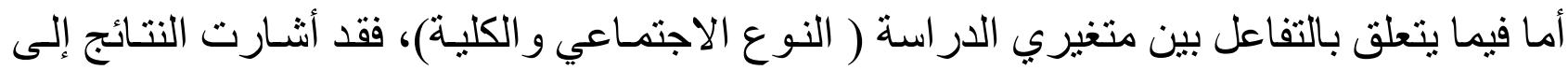

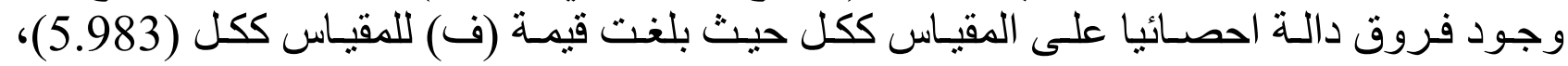

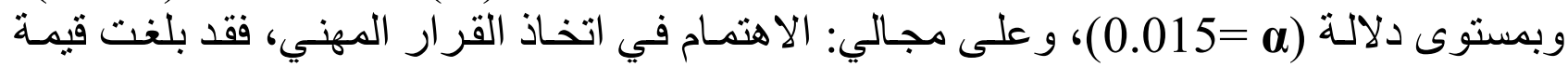

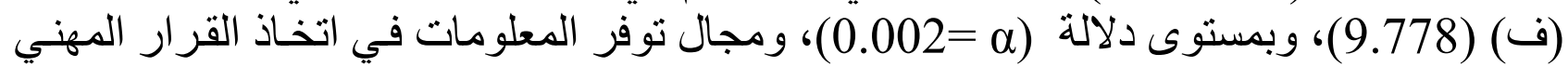

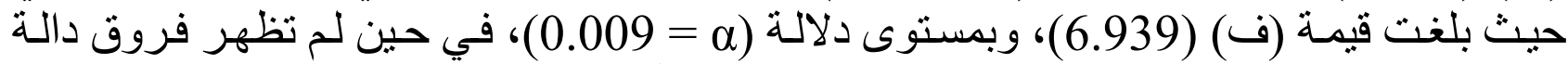

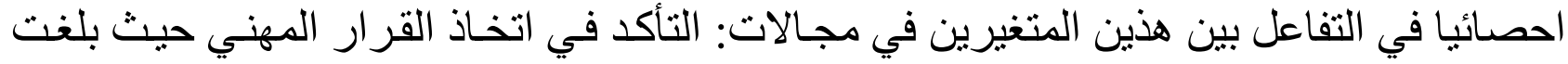

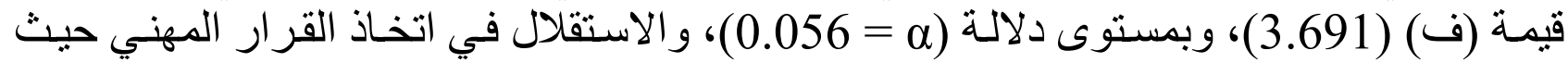

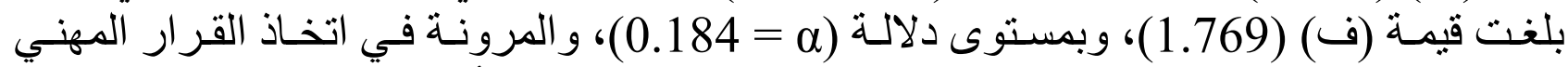

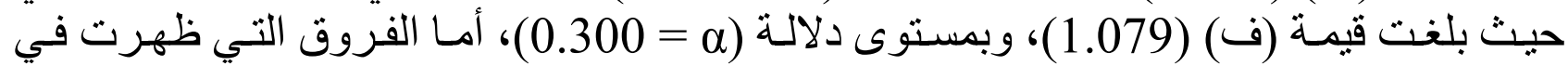
مجال الاهتمام في اتخاذ القر ار المهني فقد كانت لصالح الذكور في في الكليات الانسـانية و الثكل رقم (1) يوضح ذللك 


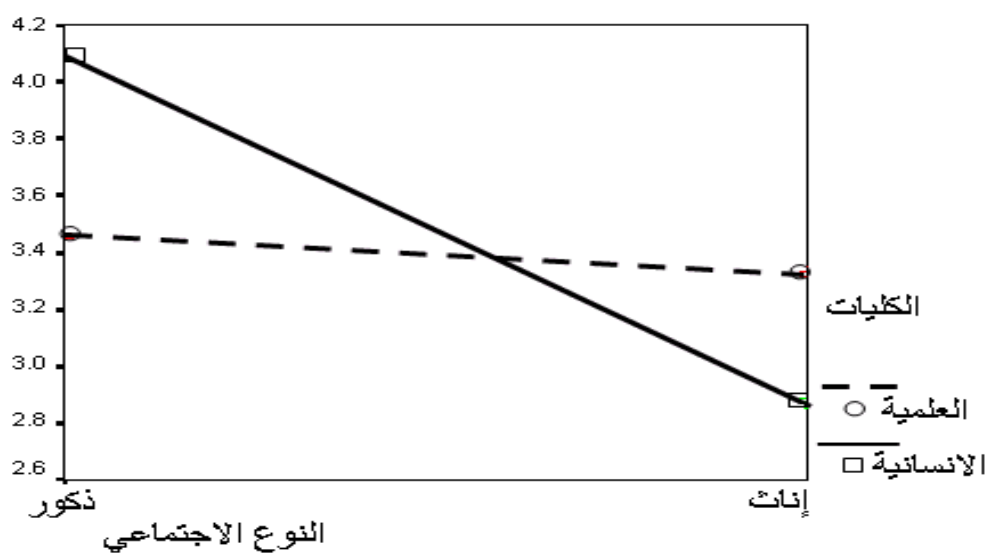

شكل رقم (1) دلالة الفروق في التفاعل بين متغيري النوع الاجتماعي و الكلية لمجال الاهتمام ولمجال توفر المعلومـات في اتخـاذ القرار المهني فقد جـاءت الفروق لصـالح الذكور في الكليات الانسانية، وكما هو موضح في الثكل رقم (2) الآتي:

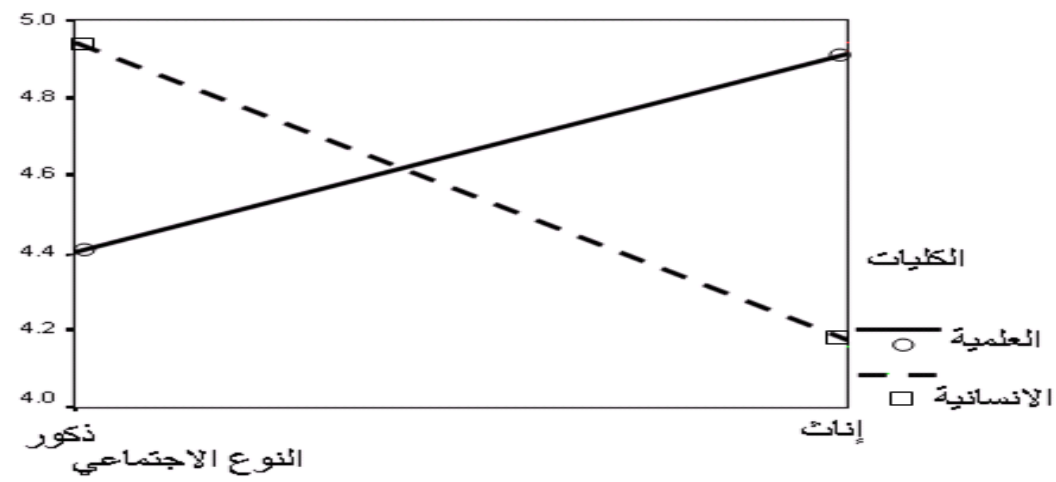

شكل رقم (2) دلالة الفروق في التفاعل بين متغيري النوع الاجتماعي و الكلية لمجال توفر المعلو مات منغيري

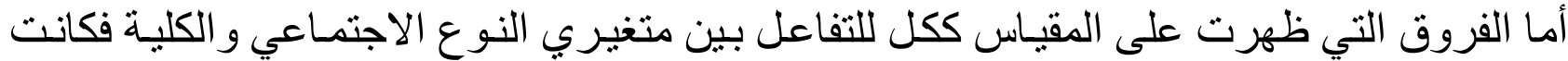
لصالح الذكور في الكليات الانسانية أيضا، وكما هو موضح في الثكل رقف (3).

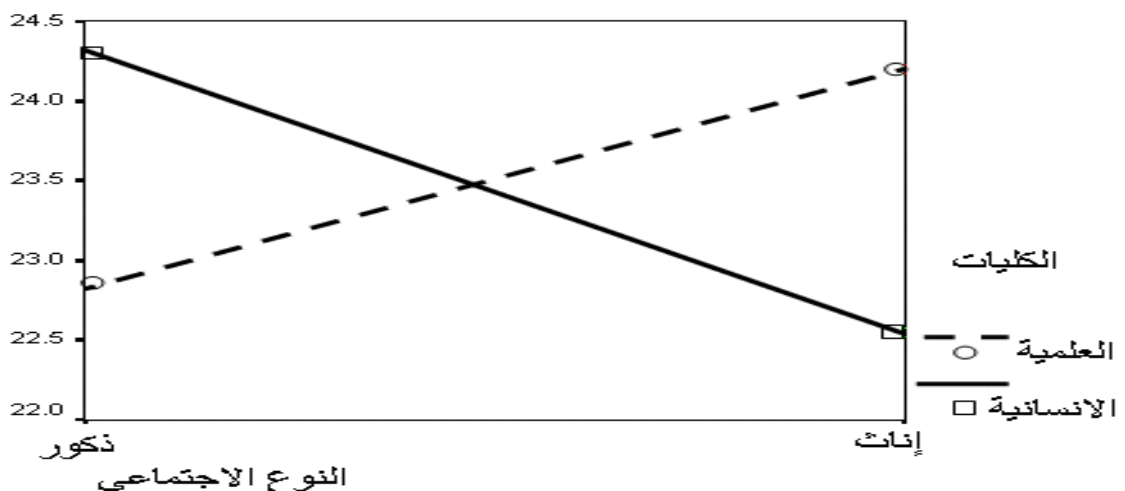

شكل رقم (3) الفروق الدالة احصائيا على التفاعل بين متغيري النوع الاجتماعي و الكلية للمقباس ككل 


\section{مناقشة النتائج المتعلقة بالسؤال الأول}

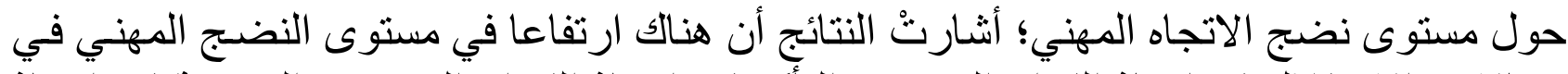

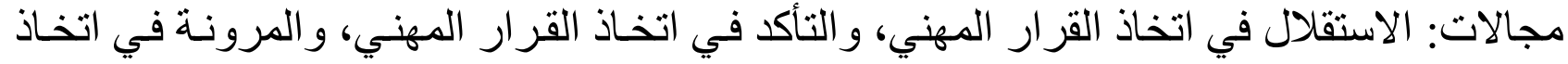

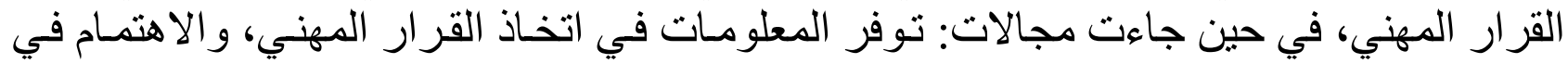

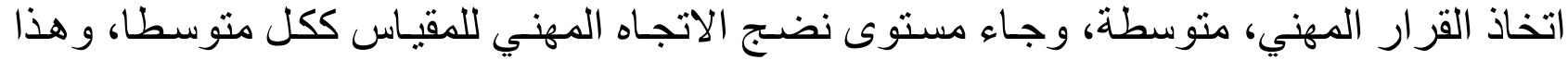

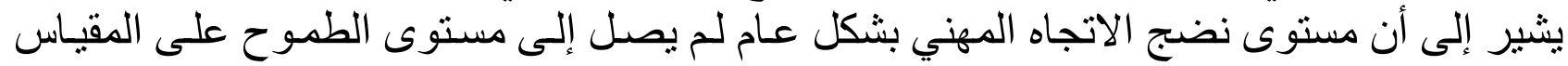

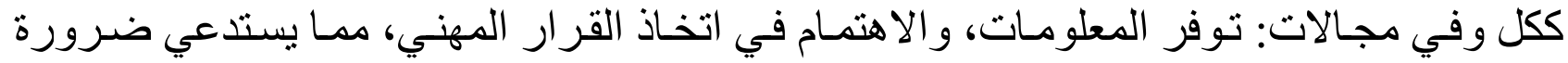

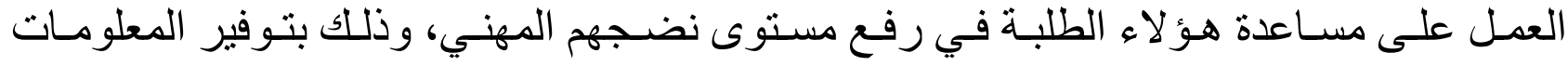

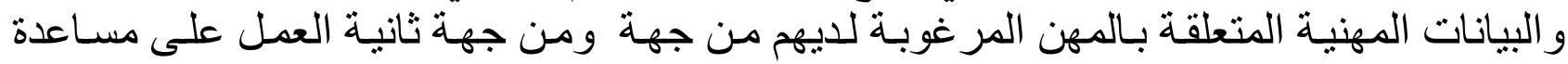

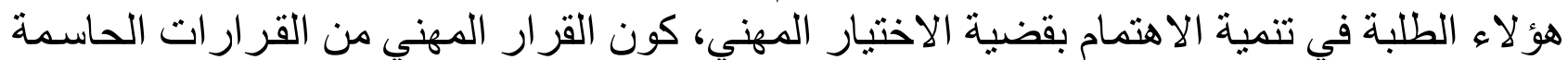

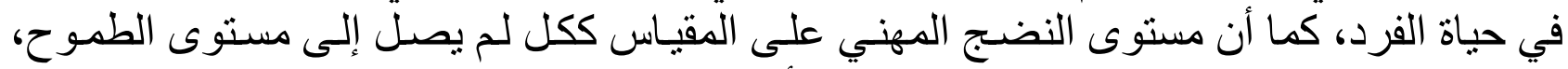

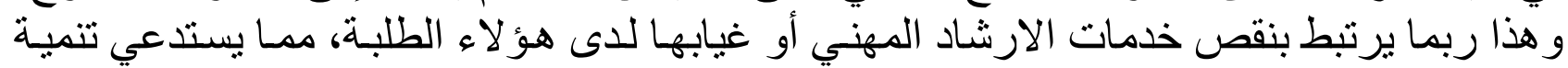
جوانب تتعلق بمجالات النضج المهني التي بتضضمنها المقياس.

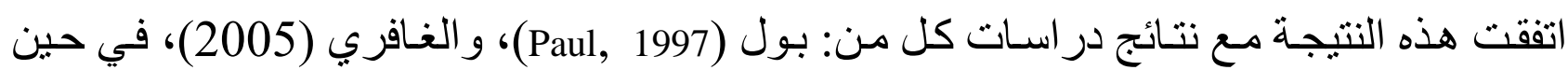

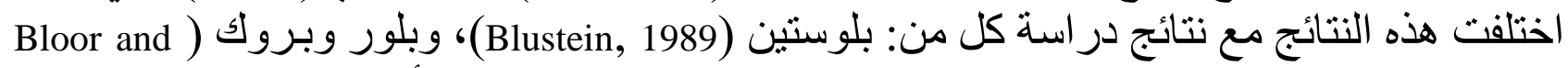

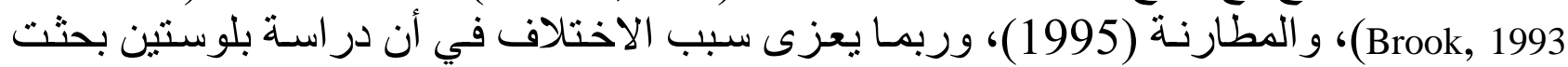

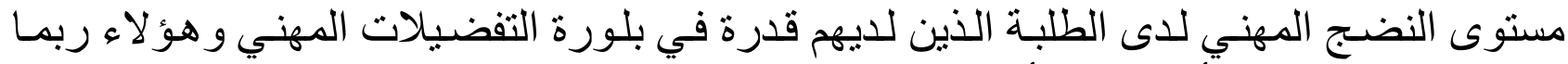
يكون مستوى نضجهم أعلى، كما أثنار ا بلور وبروك (Bloor and Brook, 1993 ) إلى طبيعة العلاقة

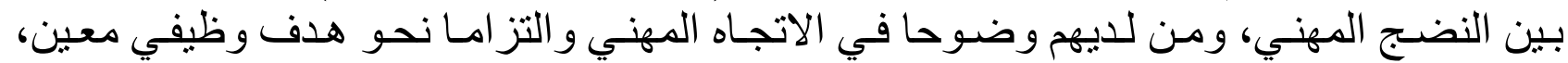

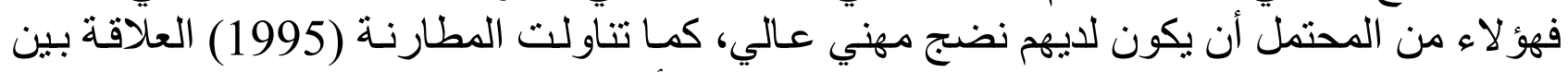
محققي الهوية النفسية و النضـج المهني، ومن المفترض أنس أن يكون مستوى النضـج المهني لمحققي

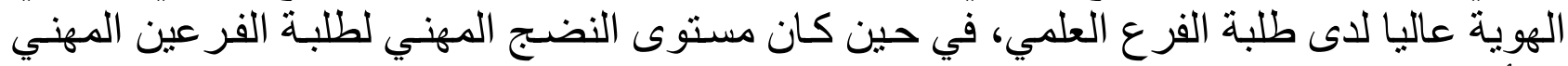

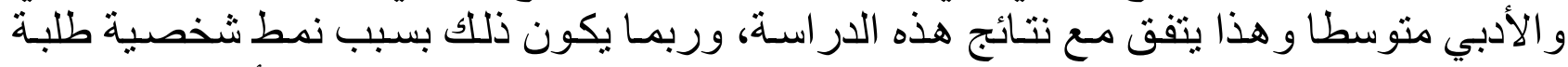
الفرع العلمي وقدر اتهم العقلية، التي تثفق مع الميول العلمية، وتختلف مع الميول دوه الأدبية.

\section{مناقشة التتائج المتعلقة بالسؤال الثاني}

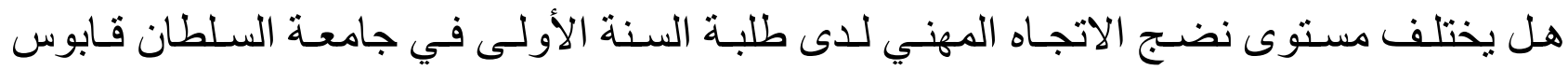
باختلاف النوع الاجتماعي (ذكور، إناث) و الكلية (إنسانية، علمية) و التفاعل بينهما؟ فقد أثـارت النتائج إلى أنه لا توجد فروق في متغير النوع الاجتمـاعي على المقيـاس ككل وكذلك الته

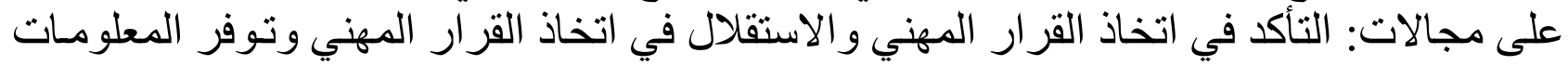

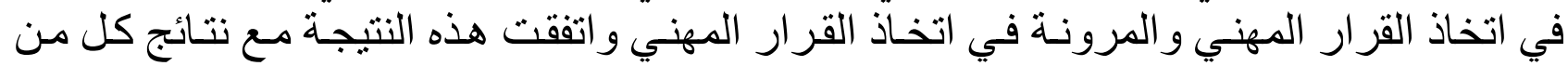

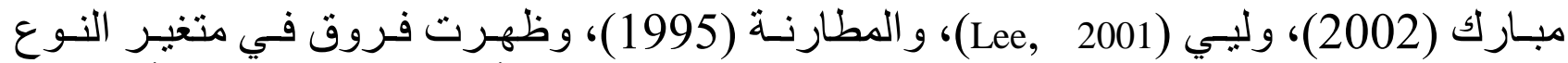

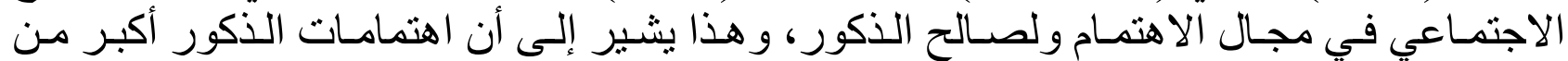

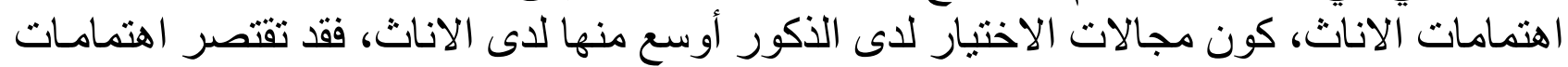

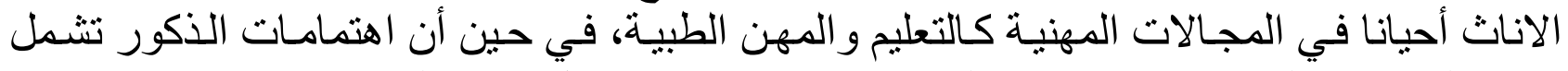
جميع المجالات المهنية. و اتفقت هذه النتيجة مع نتائج در اسـة كل من : العثيبي ( Achebe, 1982 (

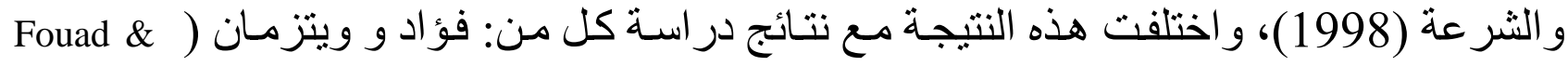


(Weitzman, 1988 )، ولوزو(Luzzo, 1995 B)، وأبو دلو (1997)، وبـاول (Powell, 2001)، وربما

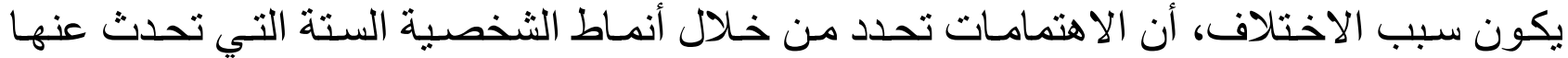

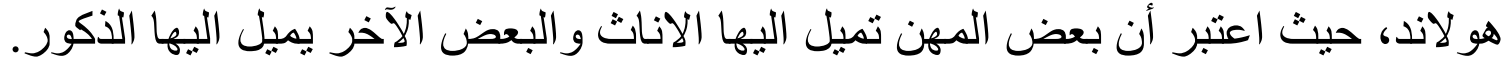

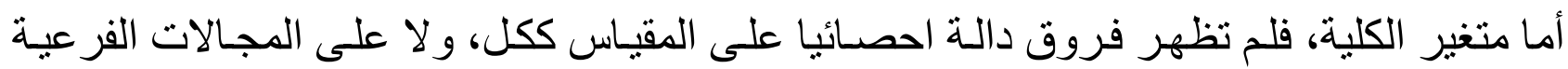

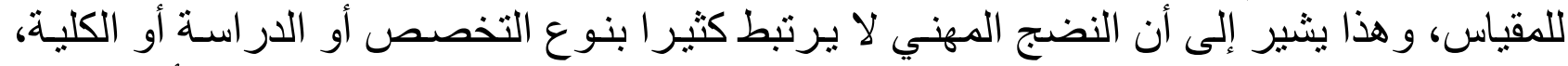

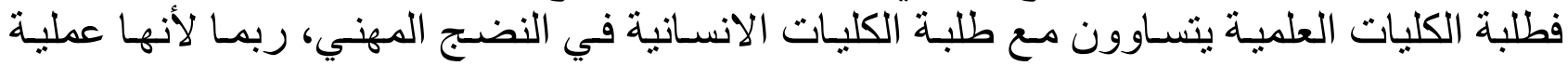

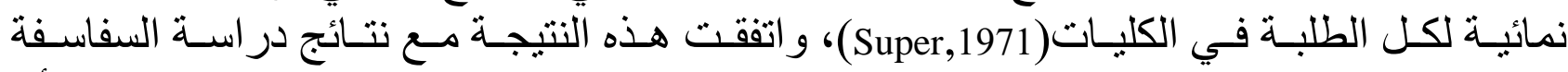

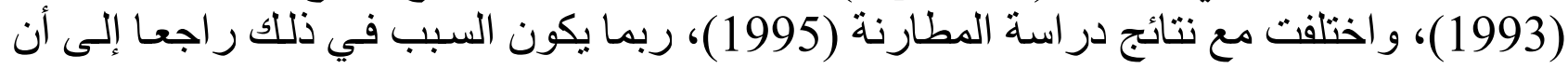

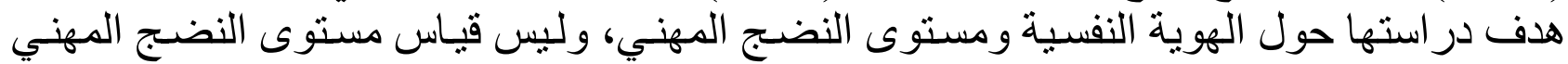

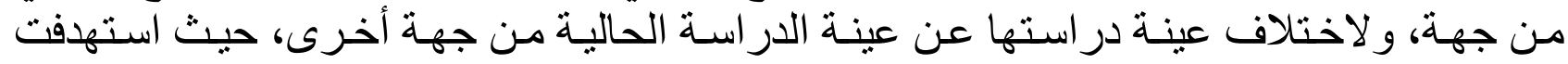
الدر اسة الحالية طلبة الجامعة فيما استهدفت المطارنة طنافة علبة الصف التف الثاني الثانوي.

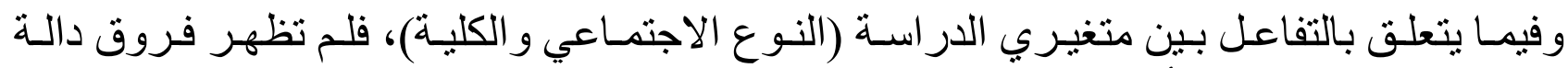

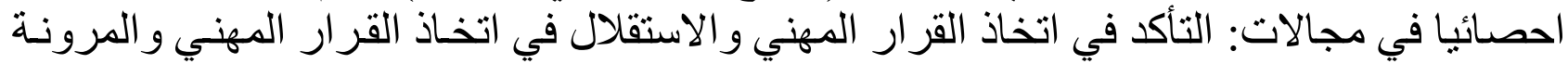

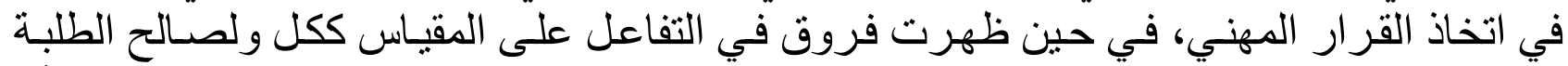

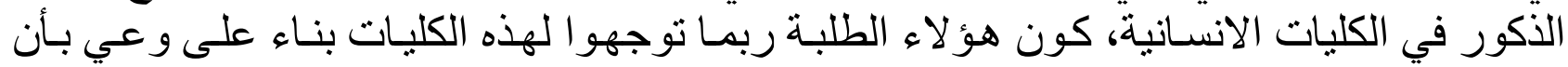

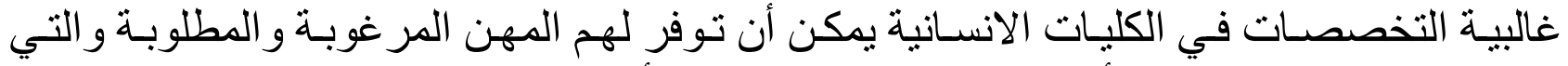

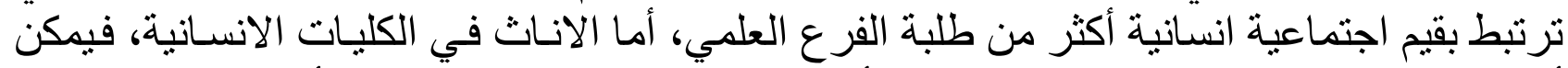

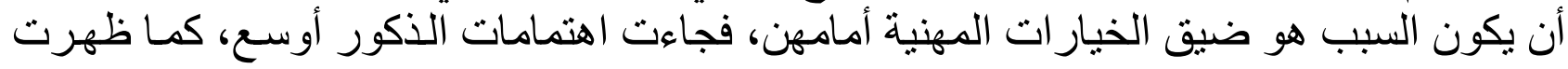

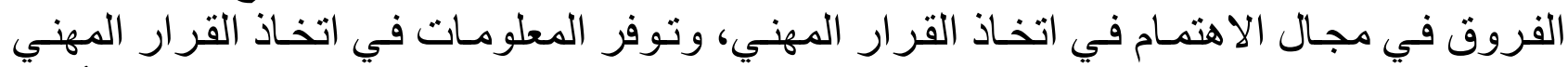

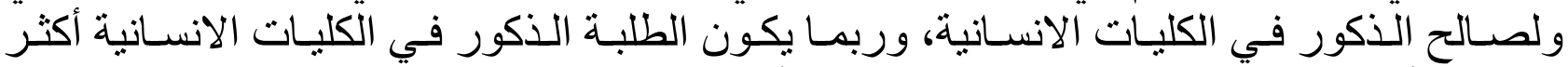

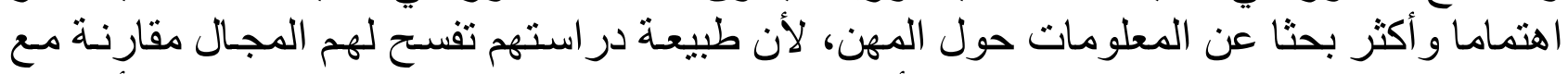

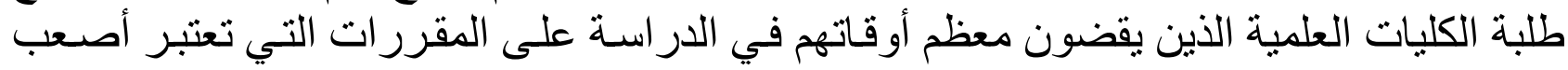

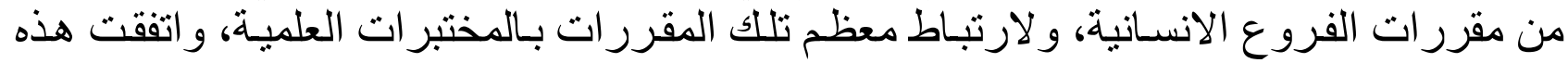
النتيجة مع نتائج در اسة مطر (1986).

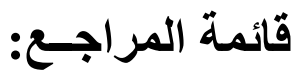

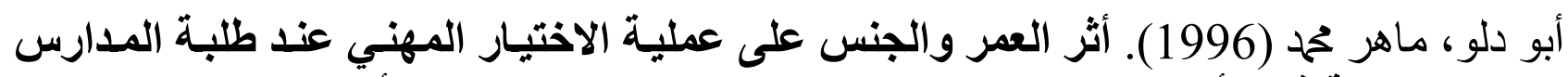

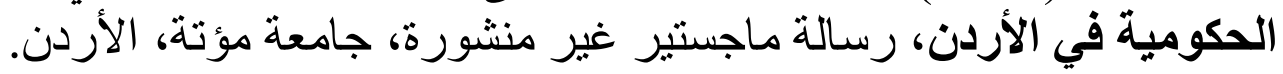

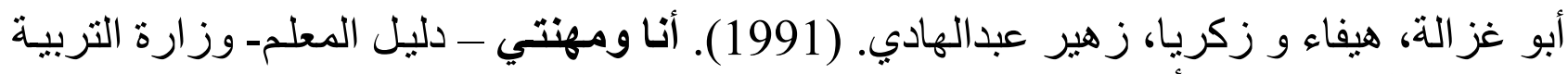
و التعليم، عمان، الأردن.

جامعة السلطان قابوس. (2006). الخلاصـة السنوية لأعداد الطلبـة في الجامعة، عمـادة القبول و التسجيل. سلطنة عمان.

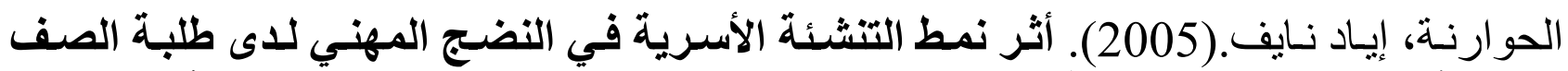
الأول الثانوي في محافظة الكرلك. رسالة ماجستير غير منشورة فئ، جامعة مؤتنة، الأردن. 
الزعبي، أحمد حمد(2003) ـ التوجيه والارشاد النفسي. دار الفكر، دمشق، ،سوريا. زهران، حامد عبدالسلام. (1998) التوجيه والارشاد النفسي( ط 3 ) ). عالم الكتاب: القاهرة.

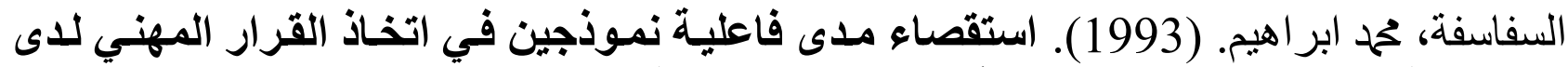

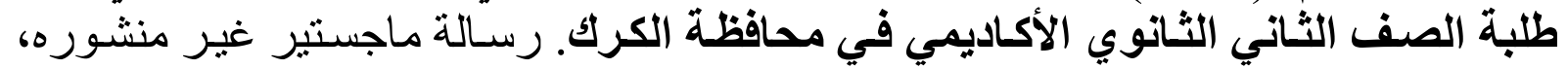
جامعة مؤنة، الأردن.

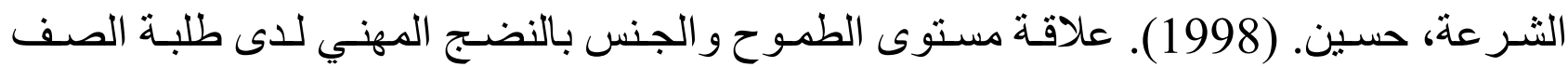
الثاني الثانوي. مؤتة للبحوث والدان.

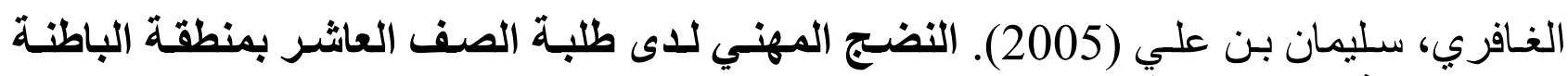

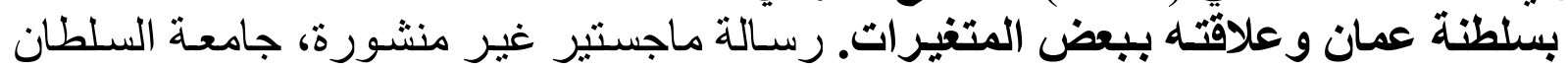
قابوس، سلطنة عمان.

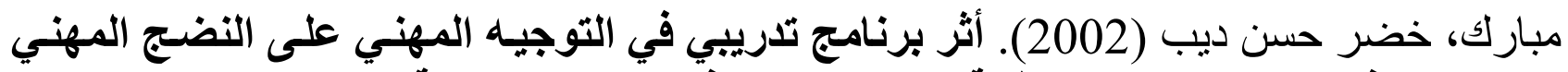

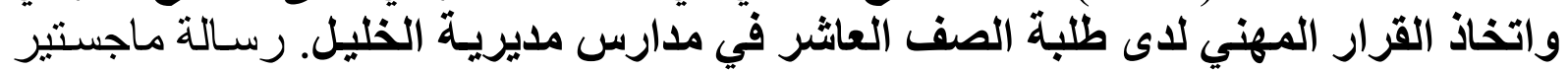
غير منشوره، جامعة القدس، فلسطين.

المشعان، عويد سلطان (1993). التوجيه المهني( ط1). مكتبة الفلاح، الكويت.

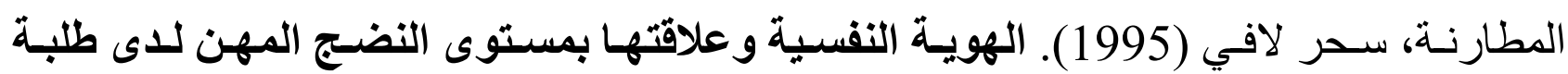

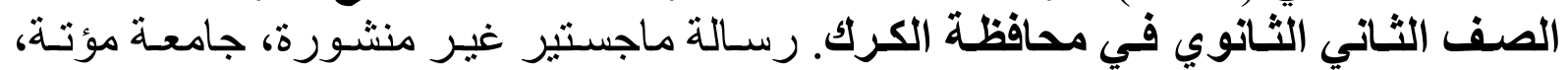

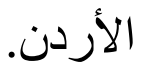

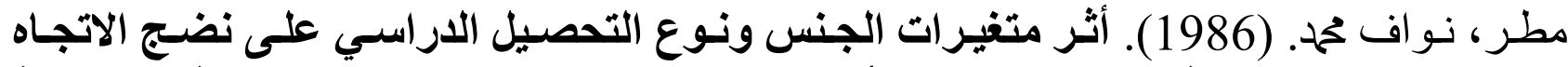

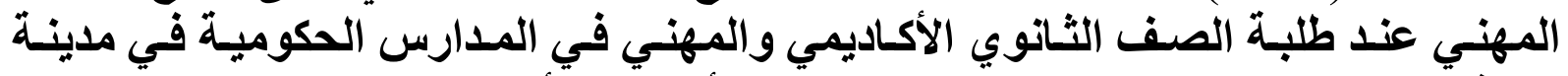

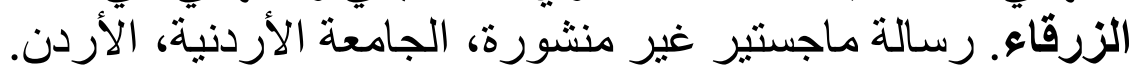

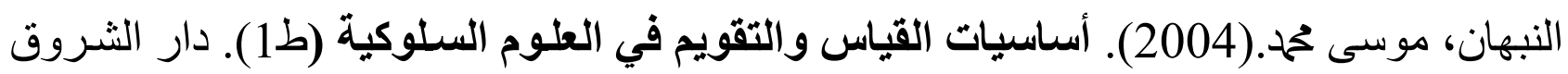
للنشر و التوزيع، عمان.

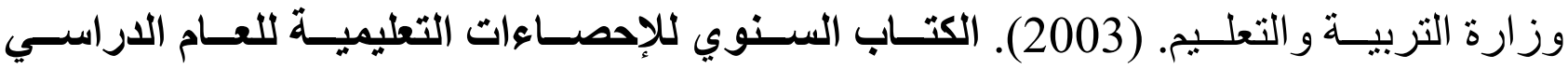
(2004/2003م)، الاصدار الر ابع و الثلاثون، مسقط: مطبعة مزون.

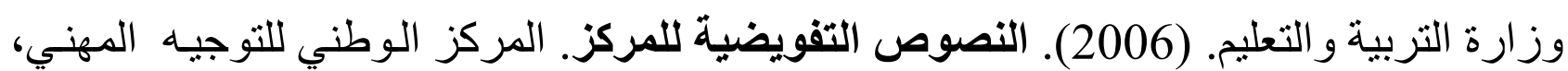
مسقط.

\section{ARABIC REFERENCES IN ROMAN ALPHABET}

'Abu Dalaw, Mahir Muhamad (1996). 'Athar Aleumr Waljuns Ealaa Eamaliat Alaikhtiar Almahnii Eind Tlbt Almadaris Alhukumiat Fi Al'urduni, Risalat Majsatayr Ghyr Manshurat, Jamieatan Mutat, Al'urdunn.

'Abu Ghazalat, Hifa' W Zakriaa, Zahir Eibdalhadi. (1991). 'Ana Wamihnati - Dalil Almelm- Wizarat Altarbiat Waltaelimi, Euman, Al'urdunn.

Jamieat Alsultan Qabus. (2006). Alkhalasat Alsanawiat Li'aedad Altalabat Fi Aljamieati, Eimadat Alqabul Waltasjili. Saltanat Eaman.

Alhawarnat, 'liad Nayf.(2005). 'Athar Namat Altanshiat Al'asriat Fi Alnadj Almahnii Ladaa Tlbt Alsafi Al'awal 
Althaanawii Fi Muhafazat Alkark. Risalat Majstayr Ghyr Manshurat, Jamieatan Mutat, Al'urdunn.

Alzaebi, 'Ahmad Mahmd(2003) . Altawjih Walairshad Alnafsi. Dar Alfukr, Dimashq, ,Suria.

Zahran, Hamid Ebdalslam. (1998) Altawjih Walairshad Alnafsi( T 3 ). Ealam Alkitab: Alqahirat.

Alsafasifat, Muhamad Abrahym. (1993). Aistiqsa' Madaa Faeiliat Namudhijin Fi Aitikhadh Alqarar Almahnii Ladaa Tlbt Alsafi Alththani Althaanawii Al'ukadimii Fi Muhafazat Alkark. Risalat Majstayr Ghyr Minshurihi, Jamieat Mutat, Al'urdunn.

Alshirieat, Husayn. (1998). Ealaqat Mustawaa Altumuh Waljuns Bialnadj Almahnii Ladaa Tlbt Alsafi Alththani Althaanwi. Mutat Lilbihwth Waldirasat, 13(5),10-33.

Alghafiri, Sulayman Bin Eali (2005). Alnadj Almahniu Ladaa Tlbt Alsafi Aleashir Bimintaqat Albatinat Bisiltanat Eamman Waealaqatih Bibaed Almutghayrat. Risalat Majstayr Ghyr Manshurat, Jamieat Alsultan Qabus, Saltanat Eaman.

Mubarak, Khadir Hasan Dib (2002). 'Athar Barnamaj Tadribiin Fi Altawjih Almahnii Ealaa Alnadj Almahnii Waitikhadh Alqarar Almahnii Ladaa Tlbt Alsafi Aleashir Fi Madaris Mudiriat Alkhalil. Risalat Majstayr Ghyr Minshurihi, Jamieat Alqudsi, Filastin.

Almusheani, Eawayd Sultan (1993). Altawjih Almahni( Ta1). Maktabat Alfalahi, Alkuayt.

Almatarinat, Sihr Lafi (1995). Alhuiat Alnafsiat Waealaqataha Bimustawaa Alnadj Almahini Ladaa Tlbt Alsafi Alththani Althaanawii Fi Muhafazat Alkark. Risalat Majstayr Ghyr Manshurat, Jamieatan Mutat, Al'urdunn.

Matir, Nawaf Mahmud. (1986). 'Athara Mutaghayirat Aljins Wanawe Altahsil Aldirasii Ealaa Nadj Alaitijah Almahnii Eind Tlbt Alsafi Althaanawii Al'ukadimii Walmahnii Fi Almadaris Alhukumiat Fi Madinat Alzrqa'. Risalat Majsatayr Ghyr Minshurati, Aljamieat Al'urduniati, Al'urdunn.

Alnubhan, Musaa Mahmd.(2004). 'Asasiaat Alqias Waltaqwim Fi Aleulum Alsilukia (T1). Dar Alshuruq Lilnashr Waltawziei, Eaman.

Wizarat Altarbiat Waltaelim. (2003). Alkitab Alsanawiu Lil'iihsa'at Altaelimiat Lileam Aldirasii (2003/2004m), Al'iisdar Alrrabie Walthalathun, Masqata: Mutbaeat Muzawn.

Wizarat Altarbiat Waltaelim. (2006). Alnusus Altafwidiat Lilmarkazi. Almarkaz Alwatanii Liltawjih Almahnii, Masqat.

\section{REFERENCE LIST}

Achebe, C.H. (1982). Assessing the Vocational Maturity of Student in East Central State of Nigeria. Journal of Vocational Behavior, 20, 153- 161.

Bloor, D. \& Brook, J. (1993). Career Development of Student Pursuing Higher Education. Journal of Educational Studies, 28 (1), 57-68.

Blustein, D. L. (1988). A Canonical Analysis of Career Choice Crystallization and Vocational Maturity. Journal of Counseling Psychology, 35, (3), 294-297.

Blustein, D. L, Devenis, L. E \& Kideny, B.K (1989). Relationship Between the Identity Formation Process and Career Development. Journal of Counseling Psychology. 36(2), 196-202.

Crites, J. O. (1971).The Maturity of Vocational Attitudes In Adolescence. Washington, DC: American Personnel and Guidance Association.

Crites, J.O. (1978). Administration and Use Manual for The Career Maturity Inventory. Monterey, CTB/McGraw-Hill.

Croker, L. \& Algina, J. (1986). Introduction To Classical and Test Theory. Rinehart and Winston, Inc.

Darrell, F.P., \& Darrell Anthony,L. (1998). Evaluating Factors Associated With the Career Maturity of High School Students. Career Development Quarterly, 47 (2), 58-145.

Fouad, N. A \& Weitzman, L.(1988). The Construct of Career Maturity in the United States and Israel. Jornal of Vocational Behavior, 32, 49-59. 
Lee,K.K (2001). Across-Cultural study of the career maturity Corean and United States High School Student. Journal of Career Development, 28(1), 43-57.

Levinson, E. Ohler, D. Caswell, S.Kiewra, K.(1998).Six Approaches To the Assessment of Career Maturity. Journal of Counseling Development, 76, 450- 482.

Luzzo, Darrell. (1995 A). The Relationship Between Career Aspiration Current Occupation Congruence and the Career Maturity of Undergraduate. Journal of Employment Counseling, 32, (3), 132-140.

Luzzo, D.A. (1995 B). Gender Differences in College Student' Career Maturity and Perceived Barriers in Career development. Journal of Counseling \& Development, 73(3), 319-322.

Mark, S., Edward, M.L, William, F.B , Danielle, L. D. (2003).Differences In Career Maturity Among Adjudicated and No adjudicated Male Students With And Without Disabilities. Journal of Employment Counseling, 40, 3, 22-108.

Osipow, Samula. (1983). Theories of Career Development. Applenta Centaury Crafts: New York.

Paul, J. H. (1997). Achieving Career Maturity. Database ERIC, p 15.

Powell, D.F. (2001). Critical Career Decision Points and Their effect on career maturity, Dissertation Abstracts International Section A Humanities and Social Science, 61, (9-A), 3476.

Super, D.E.(1983A). The History and Development of Vocational sychology: A Personal Perspective. In Walsh, W. B. \& Osipow, S. .(Ed), Handbook of Vocational Psychology , 1, 5-38.

Super, D. E. (1983B). Assessment in Career Guidance. Toward ruly Developmental Counseling. The Personal and Guidance journal, 61, 555-562.

Super, D. E. (1971). A Theory of Vocational Development, in Peters, H. J. \& Hansen, J, C, (Eds) Vocational Guidance and Career Development $\left(2^{\text {nd }} e d\right)$, The Macmillan Company, New York.

Wayne, W.M , \& Mark, A.W. (1997). Leisure Behavior and Occupational Identity in University Student. Career Development Quarterly, 46, 2, 98-190. 